Published in final edited form as:

Endocr Pract. 2010 ; 16(Suppl 3): 1-37.

\title{
AMERICAN ASSOCIATION OF CLINICAL ENDOCRINOLOGISTS MEDICAL GUIDELINES FOR CLINICAL PRACTICE FOR THE DIAGNOSIS AND TREATMENT OF POSTMENOPAUSAL OSTEOPOROSIS
}

\author{
Nelson B. Watts, MD, FACP, MACE, John P. Bilezikian, MD, MACE, Pauline M. Camacho, \\ MD, FACE, Susan L. Greenspan, MD, FACP, FACE, Steven T. Harris, MD, FACE, Stephen F. \\ Hodgson, MD, FACP, MACE, Michael Kleerekoper, MD, MACE, Marjorie M. Luckey, MD, \\ FACE, Michael R. McClung, MD, FACP, FACE, Rachel Pessah Pollack, MD, and Steven M. \\ Petak, MD, JD, FACE, FCLM
}

\section{INTRODUCTION}

Osteoporosis is a growing major public health problem with impact that crosses medical, social, and economic lines. These guidelines have been developed by the American Association of Clinical Endocrinologists (AACE) with hopes of reducing the risk of osteoporosis-related fractures and thereby improving the quality of life for people with osteoporosis. The guidelines use the best evidence, taking into consideration the economic impact of the disease and the need for efficient and effective evaluation and treatment of postmenopausal women with osteoporosis. The intent is to provide evidence-based information about the diagnosis, evaluation, and treatment of postmenopausal osteoporosis for endocrinologists, physicians in general, regulatory bodies, health-related organizations, and interested laypersons.

\section{METHODS FOR DEVELOPMENT OF AACE CLINICAL PRACTICE GUIDELINES FOR POSTMENOPAUSAL OSTEOPOROSIS}

Evidence was obtained through MEDLINE searches and other designated reference sources. Expert opinion was used to evaluate the available literature and to grade references relative to evidence level (EL) (Table 1), based on the ratings of 1 through 4 from the 2010 AACE protocol for standardized production of clinical practice guidelines (1). In addition, recommendations were graded $\mathrm{A}$ through $\mathrm{D}$, in accordance with methods established by AACE in 2004 (Table 2) (2). Information pertaining to cost-effectiveness was included when available.

\section{EXECUTIVE SUMMARY OF RECOMMENDATIONS}

Each recommendation is labeled ' $\boldsymbol{R}$ ' in this summary. 


\subsection{What Measures Can Be Taken to Prevent Bone Loss?}

- R1. Maintain adequate calcium intake; use calcium supplements, if needed, to meet minimal required intake (Grade A; "best evidence" level or BEL 1).

- R2. Maintain adequate vitamin D intake; supplement vitamin $D$, if needed, to maintain serum levels of 25-hydroxyvitamin D [25(OH)D] between 30 and 60 ng/mL (Grade A; BEL 1).

- R3. Limit alcohol intake to no more than 2 servings per day (Grade B; BEL 2).

- R4. Limit caffeine intake (Grade C; BEL 3).

- $\quad$ R5. Avoid or stop smoking (Grade B; BEL 2).

- R6. Maintain an active lifestyle, including weight-bearing exercises for at least 30 minutes daily (Grade B; BEL 2).

\subsection{What Nonpharmacologic Measures Can Be Recommended for Treatment of Osteoporosis?}

All the foregoing measures plus the following:

- R7. Maintain adequate protein intake (Grade B; BEL 3).

- $\quad$ R8. Use proper body mechanics (Grade B; BEL 1).

- R9. Consider the use of hip protectors in individuals with a high risk of falling (Grade B; BEL 1).

- R10. Take measures to reduce the risk of falling (Grade B; BEL 2).

- R11. Consider referral for physical therapy and occupational therapy (Grade B; BEL 1).

\subsection{Who Needs to Be Screened for Osteoporosis?}

- R12. Women 65 years old or older (Grade B; BEL 2).

- R13. Younger postmenopausal women at increased risk of fracture, based on a list of risk factors (see section 4.5) (Grade C; BEL 2).

\subsection{How Is Osteoporosis Diagnosed?}

- R14. Use a central dual-energy x-ray absorptiometry (DXA) measurement (Grade B; BEL 3).

- R15. In the absence of fracture, osteoporosis is defined as a T-score of -2.5 or below in the spine (anteroposterior), femoral neck, or total hip (Grade B; BEL 2).

- R16. Osteoporosis is defined as the presence of a fracture of the hip or spine (see section 4.4.2) (in the absence of other bone conditions) (Grade B; BEL 3).

\subsection{How Is Osteoporosis Evaluated?}

- R17. Evaluate for secondary osteoporosis (Grade B; BEL 2). 
- R18. Evaluate for prevalent vertebral fractures (see section 4.7.1) (Grade B; BEL 2).

\subsection{Who Needs Pharmacologic Therapy?}

- R19. Those patients with a history of a fracture of the hip or spine (Grade A; BEL 1).

- R20. Patients without a history of fractures but with a T-score of -2.5 or lower (Grade A; BEL 1).

- R21. Patients with a T-score between -1.0 and -2.5 if FRAX (see section 4.5) major osteoporotic fracture probability is $\geq 20 \%$ or hip fracture probability is $\geq 3 \%$ (Grade A; BEL 2).

\subsection{What Drugs Can Be Used to Treat Osteoporosis?}

Use drugs with proven antifracture efficacy:

- R22. Use alendronate, risedronate, zoledronic acid, and denosumab as the first line of therapy (Grade A; BEL 1).

- R23. Use ibandronate as a second-line agent (Grade A; BEL 1).

- R24. Use raloxifene as a second- or third-line agent (Grade A; BEL 1).

- $\quad$ R25. Use calcitonin as the last line of therapy (Grade C; BEL 2).

- R26. Use teriparatide for patients with very high fracture risk or patients in whom bisphosphonate therapy has failed (Grade A; BEL 1).

- R27. Advise against the use of combination therapy (Grade B; BEL 2).

\subsection{How Is Treatment Monitored?}

- R28. Obtain a baseline DXA, and repeat DXA every 1 to 2 years until findings are stable. Continue with follow-up DXA every 2 years or at a less frequent interval (Grade B; BEL 2).

- R29. Monitor changes in spine or total hip bone mineral density (BMD) (Grade C; BEL 2).

- R30. Follow-up of patients should be in the same facility, with the same machine, and, if possible, with the same technologist (Grade B; BEL 2).

- R31. Bone turnover markers may be used at baseline to identify patients with high bone turnover and can be used to follow the response to therapy (Grade C; BEL 2).

\subsection{What Is Successful Treatment of Osteoporosis?}

- R32. BMD is stable or increasing, and no fractures are present (Grade B; BEL 2). 
- R33. For patients taking antiresorptive agents, bone turnover markers at or below the median value for premenopausal women are achieved (see section 4.9) (Grade B; BEL 2).

- R34. One fracture is not necessarily evidence of failure. Consider alternative therapy or reassessment for secondary causes of bone loss for patients who have recurrent fractures while receiving therapy (Grade B; BEL 2).

\subsection{How Long Should Patients Be Treated?}

- R35. For treatment with bisphosphonates, if osteoporosis is mild, consider a "drug holiday" after 4 to 5 years of stability. If fracture risk is high, consider a drug holiday of 1 to 2 years after 10 years of treatment (Grade B; BEL 1).

- R36. Follow BMD and bone turnover markers during a drug holiday period, and reinitiate therapy if bone density declines substantially, bone turnover markers increase, or a fracture occurs (Grade C; BEL 3).

\subsection{When Should Patients Be Referred to Clinical Endocrinologists?}

- R37. When a patient with normal BMD sustains a fracture without major trauma (Grade C; BEL 4).

- R38. When recurrent fractures or continued bone loss occurs in a patient receiving therapy without obvious treatable causes of bone loss (Grade C; BEL 4).

- R39. When osteoporosis is unexpectedly severe or has unusual features (Grade C; BEL 4).

- R40. When a patient has a condition that complicates management (for example, renal failure, hyperparathyroidism, or malabsorption) (Grade C; BEL 4).

\section{EVIDENCE-BASED DISCUSSION OF RECOMMENDATIONS}

\subsection{Definition of Postmenopausal Osteoporosis}

Postmenopausal osteoporosis is defined as "a (silent) skeletal disorder characterized by compromised bone strength predisposing to an increased risk of fracture. Bone strength reflects the integration of 2 main features: bone density and bone quality" (3). Although the idea of "bone quality" is conceptually useful (4 [EL 4], 5 [EL 4]), except for bone turnover markers, methods are not currently available for the clinical assessment of other properties of bone that determine bone strength. Thus, for now and the near future, measurement of bone density remains the primary technique for the prefracture diagnosis of osteoporosis and for monitoring treatment.

In 1994, a Working Group of the World Health Organization (WHO) established an operational definition of postmenopausal osteoporosis based on BMD expressed as a T-score (Table 3) (4 [EL 4]). The T-score compares an individual's BMD with the mean value for young normal persons and expresses the difference as a standard deviation (SD) score. 
Although the WHO criteria were not intended to serve as references for treatment decisions, they are often used for this purpose. The WHO criteria are also useful for making public health and health policy decisions. In addition, the WHO criteria are commonly accepted as standards for research purposes in terms of criteria for inclusion in clinical trials.

\subsection{Background of Postmenopausal Osteoporosis}

Osteoporosis is a well-defined and growing public health problem. More than 10 million Americans have osteoporosis, and more than 34 million others have low bone mass (6 [EL 4]) and are therefore at increased risk for developing osteoporosis and for fracturing. About $80 \%$ of these subjects are women, most of them postmenopausal. At age 50 years, the lifetime risk of developing fractures is about $39 \%$ for white women and $13 \%$ for white men (7 [EL 3]). Although white women are most often affected, women of all races and all ethnic origins are at risk for osteoporosis and fracture. Although osteoporosis can also develop in men and younger women, these guidelines are limited to postmenopausal women.

By age 60 years, half of the white women in the United States have osteopenia (low bone mass) or osteoporosis (8 [EL 3]). Low BMD at the femoral neck (T-score of -2.5 or below) is found in $21 \%$ of postmenopausal white women, $16 \%$ of postmenopausal Mexican American women, and $10 \%$ of postmenopausal African American women (8 [EL 3]). The mean femoral neck T-score for 75-year-old women is -2.5 (9 [EL 3]). More than $20 \%$ of postmenopausal women have prevalent vertebral fractures (10 [EL 3]).

In 2005, 2 million fractures were attributed to osteoporosis (Fig. 1) (11 [EL 3]). Of these, $71 \%$ occurred in women. The direct cost was approximately $\$ 17$ billion, $94 \%$ of which was attributable to fractures at nonvertebral sites (Fig. 2); 57\% was spent on inpatient care, 30\% was spent on long-term care, and 13\% was spent on outpatient care (11 [EL 3]). This figure does not include lost productivity, unpaid caregiver time, transportation, and social services. Many more women have osteoporotic fractures (1.4 million) (11 [EL 3]) than new strokes $(373,000)$ (12 [EL 3]), heart attacks (345,000) (12 [EL 3]), or invasive breast cancer $(213,000)$ (13 [EL 3]) combined, according to recent statistics (2004 to 2006) (Fig. 3).

Among all osteoporotic fractures, hip fractures are the most serious. The mortality during the first year after hip fracture is more than $30 \%$ for men and about $17 \%$ for women (14 [EL $2])$. More than half of hip fracture survivors will require skilled care away from their homes, and many will have some degree of permanent disability (15 [EL 2]). Vertebral and forearm fractures are also associated with a major socioeconomic impact. Vertebral fractures cause about 70,000 hospital admissions annually (16 [EL 3]) and generate more than 66,000 office visits (17 [EL 3]). Chronic pain and deformity are common, and surgical intervention is sometimes required (7 [EL 3]). Fractures of the forearm generate about 530,000 office visits annually (17 [EL 3]) and also often result in substantial disability (18 [EL 3]).

By the year 2050, the number of people beyond age 65 years in the United States will increase from 32 million to 69 million, and more than 15 million people will exceed 85 years of age (11 [EL 3]). The incidence of hip and spine fractures increases with advancing age. From 2005 to 2025, investigators estimate that the number of osteoporosis-related 
fractures will increase from 2 million to 3 million, and the associated cost will increase from $\$ 17$ billion to $\$ 25$ billion (11 [EL 3]).

Early efforts to address osteoporosis and resulting fractures focused primarily on diagnosis, evaluation, and treatment, strategies that resulted in several major accomplishments. Important risk factors and secondary causes of osteoporosis were identified, and diagnosis and case finding were improved when Medicare abandoned its prohibition against osteoporosis screening in the late 1990s. Bisphosphonate therapy was shown to reduce fracture incidence and to have a salutary effect on bone loss. More recently, the availability of an anabolic treatment (teriparatide) has added to the therapeutic armamentarium.

Despite progress on several fronts, there is still room for improvement. Age-adjusted rates for hip fracture declined between 1980 and 2006, by $1.4 \%$ per year in women and $0.06 \%$ per year in men (19 [EL 3]). This decline seems even more significant in that the rate of fatal falls among elderly white women during the same period increased from 20.3 to 32.8 per 100,000 population-an increase of $61.6 \%$ (20 [EL 3]).

The reasons for these changes are not clear, but authors have speculated that the increase in falls was due to an increase in life expectancy (from 75.5 years in 1993 to 77.6 years in 2003) (20 [EL 3]) and therefore an increase in the susceptible population. They have further suggested that the dramatic decline in hip fracture admissions among white women is related, at least in part, to effective screening and therapy (20 [EL 3]). Similar decreases in fracture risk have been reported in Canada (21 [EL 3]), Finland (22 [EL 3]), Sweden, Australia, and Switzerland (23 [EL 3], 24 [EL 2], 25 [EL 3]).

Despite these advances, less than a third of the cases of osteoporosis have been diagnosed (26 [EL 2]), and only a seventh of the American women with osteoporosis receive treatment (27 [EL 3]).

\subsection{Pathogenesis and Pathophysiology of Postmenopausal Osteoporosis}

Low bone mass and skeletal fragility in adults may be the result of low peak bone mass in early adulthood, excessive bone loss in later life, or both.

The skeleton is constantly changing throughout life. During childhood and adolescence, it changes in size, shape, and constituents by a process known as modeling. Change in shape and size is complete with epiphyseal closure at the end of puberty, followed by a period of consolidation for 5 to 10 years (depending on the skeletal site) until peak adult bone mass is attained, which usually occurs in the late teens or early 20s (28 [EL 2], 29 [EL 3]).

Approximately $70 \%$ to $80 \%$ of peak bone mass is genetically determined. Several genetic markers have been identified (30 [EL 2], 31 [EL 4], 32 [EL 3], 33 [EL 2]). Many nongenetic factors contribute, including nutrition (for example, calcium, phosphate, protein, and vitamin D), load-bearing activity, and hormones involved in growth and puberty. In addition, certain genetic diseases, such as osteogenesis imperfecta, result in low peak adult bone mass and abnormal bone quality, but discussion of these uncommon disorders is outside the scope of these guidelines. 
Once peak adult bone mass has been reached, a process called skeletal remodeling takes over, in which old bone is replaced by new bone. Remodeling is governed by the actions of osteoclasts that resorb old bone and osteoblasts that produce new bone. Much is known about the recruitment and activity of these cells, including the involvement of systemic hormones and local cytokines. Recently, the receptor activator of nuclear factor- $\kappa \beta$ (RANK), its ligand RANKL, and a decoy receptor, osteoprotegerin (OPG), have emerged as major local regulators of bone remodeling (34 [EL 4]). RANKL, synthesized by osteoblasts and stromal cells and present in the bone microenvironment, binds to RANK, expressed in osteoclast progenitor cells in the bone marrow, and promotes osteoclastogenesis. OPG is also synthesized by osteoblasts and stromal cells and serves as a decoy receptor for RANKL, preventing the binding of RANKL to RANK. Regulation of osteoclast activity depends, at least in part, on the balance between RANKL and OPG. The relative amount of these 2 molecules is governed, in turn, by systemic hormones (for example, estrogen), local factors (such as interleukin-6 and tumor necrosis factor), and perhaps other factors as well. The triggering mechanisms that stimulate the cascade of activities that lead to remodeling of sitespecific quantities of bone are not known. It is well documented, however, that this bone remodeling process is in balance (that is, the rate of bone formation equals the rate of bone resorption) through at least the fifth decade of life in healthy individuals. Up to this age, there is generally little net loss or gain of bone. Wnt signaling is an important pathway that influences osteoblastic bone formation. It is complex and involved in many physiologic systems beyond just the skeleton. A detailed description of this pathway is beyond the scope of these guidelines, but the key components that have thus far been most studied with respect to skeletal physiology include the frizzled family of G protein-coupled receptor proteins, low-density lipoprotein receptor-related protein 5 encoded by the $L R P 5$ gene and associated with high bone mass in affected families, cathepsin K, Dikkopf-related protein 1, and sclerostin.

In women, the hormonal changes that occur throughout perimenopause and the immediate postmenopausal years stimulate RANKL production (both directly and indirectly), leading to accelerated bone loss. Most data suggest that the bone turnover rate (and bone loss) accelerates 3 to 5 years before the last menstrual period and slows again 3 to 5 years after the last menstrual period. With the accelerated bone turnover rate, bone balance is disturbed because there is greater net loss than gain in each of the bone remodeling units that are activated. The mean rate of bone loss during this period is about $1 \%$ per year, or about $10 \%$ during the menopausal transition.

In contrast to menopause-associated bone loss, age-related bone loss begins in the sixth decade of life in men and women and proceeds at a slower rate, about $0.5 \%$ per year. Although age-related bone loss involves the same imbalance in the bone remodeling unit as occurs in the menopause-related bone loss, the initiating process is not as clear.

In conjunction with loss of bone mass due to menopause or aging, there are also changes in bone quality. The somewhat nebulous concept of bone quality includes disruption of the microarchitectural elements of cancellous (trabecular) bone, expansion of the periosteal envelope and trabecularization of the endocortex (that is, cortical thinning), decrease in the degree of mineralization of individual skeletal elements, and likely other as yet unknown 
factors (5 [EL 4]). Newer technologies for monitoring these architectural changes are being introduced into the research arena but are not yet generally available. Additionally, although therapies that slow the bone remodeling process (antiresorptive drugs, also called anticatabolic drugs) appear to have a limited effect on cortical bone, anabolic therapies seem to minimize and possibly reverse these adverse effects of aging on the cortical envelope. As is the case with trabecular microarchitecture, techniques for monitoring these changes longitudinally are still limited to the realm of research. Nonetheless, the importance of this abnormality in cortical bone has been well established in cross-sectional studies.

Many factors, including nutrition, vitamin D, exercise, smoking, and the presence of other diseases and medications (Table 4), can influence the rate of bone loss and the risk of fractures in individuals. Nutrition is important during aging as well as during bone growth. In particular, vitamin D deficiency, whether isolated or associated with more generalized undernutrition, has reached almost epidemic proportions throughout the world. Although severe vitamin D deficiency impairs mineralization of the skeleton, even mild to moderate vitamin $\mathrm{D}$ deficiency reduces calcium absorption and can lead to parathyroid hormone (PTH)-mediated increases in bone resorption. Vitamin D deficiency also causes impairment of muscle strength and balance, leading to an increased risk of falling.

Most osteoporosis-related fractures are the result of falls, which probably have as important a role in the pathogenesis of osteoporosis-related fractures as many of the pathways already discussed. Risk factors for falls are summarized in Table 5. A fragility fracture is defined as a fracture that results from trauma less than or equal to that from a fall from a standing height and almost always indicates decreased skeletal strength. There is increasing evidence that patients who have low bone mass are also at increased risk for fracture after more extensive trauma (35 [EL 2]).

\subsection{Clinical Features and Complications of Postmenopausal Osteoporosis}

4.4.1. Low Bone Mass_Low bone mass—as assessed clinically by measurements showing low BMD—is a major characteristic of postmenopausal osteoporosis. A strong inverse relationship exists between BMD and risk of fracture. Therefore, low BMD is a major indicator of fracture risk in women without fractures, although it is important to realize that individual patients may sustain fractures at different BMD levels and that factors other than bone density influence fracture risk (Table 5). Low BMD and bone loss are not associated with symptoms before occurrence of a fracture.

4.4.2. Fracture-Fracture is the single most important manifestation of postmenopausal osteoporosis. Osteoporosis-associated fractures may occur in any bone but are most likely to occur at sites of low BMD and are usually precipitated by a fall or injury. Vertebral compression fractures, however, may occur during routine daily activities, without a specific fall or injury. In clinical practice, it may be difficult or impossible to reconstruct the mechanical force applied to bone in a particular fall.

Hip fractures are the most serious complication of osteoporosis. Half of the patients who could walk independently previously are unable to do so 1 year after a hip fracture. Women with hip fracture have an increased mortality of $12 \%$ to $20 \%$ during the subsequent 2 years, 
whereas men with hip fracture have an increased mortality of approximately twice that. More than $50 \%$ of the survivors are unable to return to independent living; many require long-term nursing home care (36 [EL 4]). Important secondary complications of fractures are itemized in Table 6. Potential complications as well as physical manifestations of vertebral fractures are listed in Table 7 (37 [EL 3]).

\subsection{Risk Factors for Postmenopausal Osteoporosis}

For years, it has been quite clear that measurement of bone density is a good assessment technique but not enough. Clinical risk factors can be used to assess fracture risk, with or without bone density results. In February 2008, a tool called FRAX was released by WHO (38 [EL 4]) and is available online at www.shef.ac.uk/FRAX. FRAX is the best effort to date to incorporate risk factors into determination of fracture risk and is more effective in conjunction with BMD than without. Important risk factors-risks that are amenable to intervention — can be determined easily. FRAX can be used for men as well as women and is validated globally, with output and utility of results adaptable to individual populations or regional/national standards, but there are also major limitations (39 [EL 4], 40 [EL 4]).

4.5.1. Risk Factors for Low Bone Mass-Age and body weight (or body mass index) correlate with BMD in older adults. Algorithms that incorporate these indices are available to predict BMD but are not sufficiently sensitive for diagnosis or exclusion of osteoporosis (41 [EL 4]). Only BMD measurements can identify patients who have low bone mass. BMD testing is the best way to identify patients at risk for fracture before the first fracture occurs, but the use of BMD can be enhanced by the addition of information about clinical risk factors.

4.5.2. Risk Factors for Fractures-Assessment of risk factors for fractures may be useful for identifying individuals at high risk of fractures, heightening clinical awareness of osteoporosis, and developing strategies for treatment of osteoporosis and prevention of fracture.

No single risk factor is sufficient for predicting total fracture risk. Only by assessing a combination of risk factors can reliable estimates of fracture risk be made (42 [EL 2]). Important risk factors for osteoporosis-related fractures are outlined in Table 8.

A low-trauma fracture as an adult (45 years of age or older) is associated with a 1.8-fold increased risk of subsequent fracture (range, 1.6 to 1.9), after adjustment for BMD (43 [EL 2]). A prior vertebral fracture is associated with a 4-fold to 5 -fold increased risk of subsequent fracture (44 [EL 4]).

For every SD decrease in age-adjusted BMD, overall fracture risk increases by about 2-fold (range, 1.6-fold to 2.6-fold) (45-47 [EL 2]). Hip BMD predicts hip fracture better than does $\mathrm{BMD}$ at other sites (relative risk $=2.6 / \mathrm{SD}$ ), but reduced bone density at any skeletal site predicts potential fracture not only at that site but also at other sites. The risk of most fragility fractures increases progressively with advancing age. The relationship between BMD and fracture risk is significantly affected by age. For any given BMD value, older adults are at higher risk of fracture than are younger adults, as shown in Figure 4 (48 [EL 
1]). Many other factors have been found to correlate with an increased risk of fracture.

Although the strength of these individual associations with fracture risk is small, they may be important in individual patients.

Because many patients with osteoporosis have coexisting causes of bone loss (Table 9), the fracture risk profile must consider secondary osteoporosis (see section 4.8).

4.5.3. Risk of Falling-Falls magnify the risk of fractures due to other factors and are the proximate cause of most fractures in older adults (49 [EL 2]). Factors that increase the risk of falls and fractures are shown in Table 5 .

\subsection{Lifestyle and Nonpharmacologic Measures for Bone Health}

A "bone healthy" lifestyle (adequate dietary calcium and vitamin D, exercise, avoidance of tobacco, and so forth) is important for everyone-babies, children, teenagers, young adults, and patients with osteoporosis. Patients with osteoporosis may also benefit from physical therapy and other nonpharmacologic measures to strengthen bones and reduce fracture risk. Goals include the following:

- Optimize skeletal development and maximize peak bone mass at skeletal maturity

- Prevent age-related and secondary causes of bone loss

- Preserve the structural integrity of the skeleton

- $\quad$ Prevent fractures

4.6.1. Good General Nutrition-In addition to ensuring adequacy of calcium and vitamin $\mathrm{D}$, a balanced diet throughout life is important for bone health. Among young adults, anorexia nervosa and intense aerobic exercise have been associated with delayed menarche and delayed or lower peak bone mass (50 [EL 4]). This outcome may also prevail among adults who are consuming restrictive diets for weight loss or who have surgically induced weight loss. Adequate protein intake (the recommended daily protein dietary allowance in the United States is $0.8 \mathrm{~g} / \mathrm{kg}$ ) helps minimize bone loss among patients who have sustained hip fractures (51 [EL 4]). In one study, patients with hip fracture who received supplemental protein had shorter hospital stays and better functional recovery (52 [EL 1]).

4.6.2. Calcium-Adequate calcium intake is a fundamental aspect of any osteoporosis prevention or treatment program and a lifestyle issue for healthy bones at any age (Grade A; BEL 1). The recommended daily calcium intake for various populations is outlined in Table 10 (53). For women 50 years old or older, the recommended daily calcium intake is 1,200 mg. This represents the total calcium intake (diet plus calcium supplements, if applicable). When dietary intake is insufficient, calcium supplementation may be needed. Although many of the effects of increasing calcium intake on the developing skeleton are incompletely understood, it is well recognized that supplemental calcium increases bone mass in physically active children and adolescents (54-58 [EL 1-2]). 
Examining a dietary history to assess calcium intake is important. The average calcium intake for adults is about half of what is recommended, with a median of approximately 600 $\mathrm{mg} / \mathrm{d}$ in comparison with the goal of $1,200 \mathrm{mg}$ daily (59 [EL 3]). Patients with insufficient dietary calcium intake should either change their diet or receive calcium supplements. Numerous calcium supplements are available. Calcium carbonate is generally the least expensive and necessitates use of the fewest tablets. Calcium carbonate, however, may cause gastrointestinal (GI) complaints (constipation and bloating) and, in the absence of secretion of gastric acid, must be taken with meals for adequate absorption. (All calcium preparations are generally better absorbed when taken with food.) Calcium citrate is often more expensive than calcium carbonate and necessitates the use of more tablets to achieve the desired dose; however, its absorption is not dependent on gastric acid, and it may be less likely to cause GI complaints. For optimal absorption, the amount of calcium should not exceed 500 to $600 \mathrm{mg}$ per dose, irrespective of the calcium preparation. For patients requiring more than $600 \mathrm{mg}$ of calcium supplement daily, the dose should be divided.

Calcium requirements increase among older persons; thus, the elderly population is particularly susceptible to calcium deficiency. Factors that lead to calcium deficiency include decreased intestinal absorption of both calcium and vitamin D and renal insufficiency that leads to decreased activation of vitamin D. Patients with GI malabsorption, those who are taking high-dose glucocorticoids, those who have diminished gastric acid production (for example, with a history of gastric bypass, with pernicious anemia, or with use of proton pump inhibitors), those receiving antiepilepsy drugs, and even those with asymptomatic celiac disease are particularly predisposed to calcium and vitamin D deficiency.

Consideration should be given to laboratory assessment of adequacy of calcium and vitamin $\mathrm{D}$ in patients who are candidates for pharmacologic therapy.

Calcium supplementation has been shown to increase BMD slightly, but no scientific evidence supports its ability to reduce fracture risk, independent of vitamin D. The lack of evidence of an independent effect of calcium on fracture risk reduction is likely due, in part, to problems with study design and patient compliance (60-63 [EL 1]). A large study raised concerns about the risk of nephrolithiasis from calcium supplementation (62 [EL 1]); however, hypercalciuria may worsen with calcium supplementation, and participants in the study were not evaluated for renal calcium wasting. Moreover, the absolute risk of kidney stones was small (2.5\% in the calcium-supplemented group versus $2.1 \%$ in the control group). In addition, in these study subjects, the mean total calcium intake from diet and supplements was higher than currently recommended. Generally, healthy persons should not require more than $1,000 \mathrm{mg}$ of calcium supplements daily. Patients with a history of nephrolithiasis should be evaluated for the cause of renal stone formation or hypercalciuria before a decision is made about calcium supplementation.

4.6.3. Vitamin D-It is important to ensure sufficiency of vitamin D among children and adults to prevent osteoporosis (Grade A; BEL 1). Most "healthy" adults have serum 25(OH)D levels that are lower than desirable (64 [EL 2]). Vitamin D is not widely available in natural food sources. It is primarily found in fish oils (including cod liver oil), fortified milk, cereals, and breads. Vitamin D is produced in the skin by exposure to sunlight that is not blocked by sunblock agents, but not in northern or southern latitudes during winter. The 
National Academy of Sciences recommends 400 IU of vitamin D per day for normal adults 51 to 70 years old and $600 \mathrm{IU} / \mathrm{d}$ for those above 70 years old. Many experts now believe that these recommendations are too low (65 [EL 4]). For adults 50 years old or older, the National Osteoporosis Foundation recommends 800 to 1,000 IU of vitamin D per day, but many experts recommend more-1,000 to 2,000 IU per day (see http://www.aace.com/alert/ alert11302010.php) [4,000 IU per day is the "safe upper limit" (53)]—and some patients require considerably more supplementation to achieve desirable levels. Home-bound individuals with limited mobility, patients who have intestinal malabsorption, or those who are receiving long-term anticonvulsant or glucocorticoid therapy are particularly at risk for vitamin D deficiency. The currently accepted minimal level for $25(\mathrm{OH}) \mathrm{D}$ adequacy is 30 to $32 \mathrm{ng} / \mathrm{mL}$, on the basis of a growing body of evidence indicating that secondary hyperparathyroidism is increasingly common as $25(\mathrm{OH}) \mathrm{D}$ levels decline below $30 \mathrm{ng} / \mathrm{mL}$ (60 [EL 1]) and that fractional calcium absorption improves with vitamin D supplementation in patients with levels below $30 \mathrm{ng} / \mathrm{mL}$ but not in patients with levels above $30 \mathrm{ng} / \mathrm{mL}$. A reasonable upper limit, based on levels in sun-exposed healthy young adults, is $60 \mathrm{ng} / \mathrm{mL}$ (66 [EL 3]).

A meta-analysis of studies in postmenopausal women found a significant reduction in hip and nonvertebral fractures with vitamin D supplementation at doses of 700 to $800 \mathrm{IU} / \mathrm{d}$ or more (67 [EL 2]). The Women's Health Initiative (WHI) study showed a small but significant increase in hip BMD (1\%) in the group of patients who received 1,000 $\mathrm{mg}$ of calcium and $400 \mathrm{IU}$ of vitamin D per day (62 [EL 1]). In addition to the skeletal effects of vitamin $\mathrm{D}$, studies have also shown improvement in muscle strength, balance, and risk of falling (68-70 [EL 2]) as well as improvement in survival (71 [EL 2]).

Vitamin D supplements are available as ergocalciferol (vitamin $\mathrm{D}_{2}$ ) and cholecalciferol (vitamin $\mathrm{D}_{3}$ ) in strengths up to 50,000 IU per tablet. With daily dosing, vitamin $\mathrm{D}_{2}$ and $\mathrm{D}_{3}$ appear to be equally potent (72 [EL 1]), but with intermittent (weekly or monthly) dosing, vitamin $\mathrm{D}_{3}$ appears to be about 3 times more potent than vitamin $\mathrm{D}_{2}$ (73 [EL 2]). Blood levels of $25(\mathrm{OH}) \mathrm{D}$ provide the best index of vitamin $\mathrm{D}$ stores. A desirable range is between 30 and $60 \mathrm{ng} / \mathrm{mL}$, although levels up to $100 \mathrm{ng} / \mathrm{mL}$ are unlikely to result in vitamin D toxicity. Many people require vitamin D supplements of 2,000 IU per day or more to achieve desirable levels. (Cholecalciferol, 1,000 IU daily, will raise blood levels, on average, by approximately $10 \mathrm{ng} / \mathrm{mL}$.)

4.6.4. Other Dietary Supplements-Patients frequently inquire about the need for magnesium supplementation. No randomized controlled study has been done to show that the intake of magnesium decreases fracture risk or increases BMD. One study showed that adding 789 to $826 \mathrm{mg}$ of magnesium per day did not increase the rates of calcium absorption (74 [EL 1]). Individuals who are at risk for hypomagnesemia (for example, those who have GI malabsorption or chronic liver disease [alcoholics]), however, may benefit from magnesium supplementation. Magnesium may help prevent constipation, which is sometimes associated with calcium supplementation.

Excessive intake of vitamin A (more than 10,000 IU daily) should be avoided because this has been shown to have detrimental effects on bone (75 [EL 4]). In contrast, published data 
have shown that vitamin $\mathrm{K}(1 \mathrm{mg} / \mathrm{d})$ may reduce bone turnover and bone loss in postmenopausal women (76 [EL 1]). Further studies need to confirm this finding before this strategy can be part of the standard recommendations for prevention of osteoporosis.

"Natural" estrogens (isoflavones) are promoted to prevent bone loss. No conclusive data, however, support the use of these agents for increasing bone density or decreasing fracture risk (77 [EL 1], 78 [EL 1], 79 [EL 2]).

4.6.5. Alcohol-Excessive intake of alcohol should be avoided because investigators have proved that alcohol has detrimental effects on fracture risk (Grade B; BEL 2) (80 [EL 2]). The mechanisms are multifactorial and include predisposition to falls, calcium deficiency, and chronic liver disease. Chronic liver disease, in turn, predisposes to vitamin D deficiency. Postmenopausal women at risk for osteoporosis should be advised against consuming more than 7 drinks/wk, with 1 drink equivalent to $120 \mathrm{~mL}$ of wine, $30 \mathrm{~mL}$ of liquor, or $260 \mathrm{~mL}$ of beer.

4.6.6. Caffeine-Patients should be advised to limit their caffeine intake to less than 1 to 2 servings ( 8 to 12 ounces in each serving) of caffeinated drinks per day (Grade C; BEL 3). Several observational studies have shown an association between consumption of caffeinated beverages and fractures (81 [EL 3], 82 [EL 3]). Caffeine intake leads to a slight decrease in intestinal calcium absorption and an increase in urinary calcium excretion, suggesting that a moderate intake of caffeine would not be harmful to bone health. The most important effect of caffeinated beverages is that, by replacing milk in the diet, they contribute to overall inadequate calcium intake in the United States.

4.6.7. Smoking-Cigarette smoking is a risk factor that has been validated by multiple studies to increase osteoporotic fracture risk and thus should be avoided (Grade B; BEL 2). The exact mechanism is unclear but may be related to increased metabolism of endogenous estrogen or direct effects of cadmium on bone metabolism. No prospective studies have been done to determine whether smoking cessation reduces fracture risk, but a meta-analysis showed a higher risk of fractures in current smokers than in previous smokers (83 [EL 2]). Smokers should be advised on smoking cessation.

4.6.8. Exercise-Regular weight-bearing exercise (for example, walking for 30 to 40 minutes per session), and back and posture exercises for a few minutes on most days of the week (see http://www.nof.org/aboutosteoporosis/prevention/exercise) should be advocated throughout life (Grade B; BEL 2). Children and young adults who are active reach a higher peak bone mass than those who are not. In studies of young women, muscle strength appeared to correlate with BMD (84 [EL 2], 85 [EL 1]). Studies involving early postmenopausal women have shown that strength training leads to small yet significant changes in BMD. A meta-analysis of 16 trials and 699 subjects showed a $2 \%$ improvement in lumbar spine BMD in the group that exercised in comparison with the group that did not (86 [EL 2]). Among elderly patients, these exercises help slow bone loss attributable to disuse, improve balance, increase muscle strength, and ultimately reduce the risk of falls (87 [EL 2], 88 [EL 2]). These outcomes may be as important as—or even more important thanthe effects of exercise on BMD. 
Patients with severe osteoporosis should avoid engaging in motions such as forward flexion exercises, using heavy weights, or even performing side-bending exercises because pushing, pulling, lifting, and bending exert compressive forces on the spine that may lead to fracture. An initial visit with a physical therapist may help clarify what exercises are safe and unsafe to do.

4.6.9. Prevention of Falls-Falls are the precipitating cause of the majority of osteoporotic fractures, and an effective osteoporosis treatment regimen must include a program for fall prevention (Grade B; BEL 2). All patients should be counseled on fall prevention. Some measures that can be taken to avoid falls at home are outlined in Table 11. Particularly predisposed are persons who are older, are frail, have had a stroke, or are taking medications that decrease mental alertness. Although several interventions have been shown to reduce the risk of falling, none has been shown to reduce the risk of fractures, although it is logical that they would.

Hip protectors do not reduce the risk of falling. Intuitively, hip protectors should reduce the risk of fracture. Positive results have been seen in some trials, but not in all, and compliance is poor (89-94 [EL 1-3]). Hip protectors may be considered for patients who have sustained a prior hip fracture, for slender or frail patients who have fallen in the past, and for patients who have major risk factors for falling because of postural hypotension or difficulty with balance, whether they have osteoporosis or not (Grade B; BEL 1).

Elderly patients with severe kyphosis, back discomfort, and gait instability could benefit from physical and occupational therapy referral. A treatment plan that focuses on weightbearing exercises, back strengthening and balance training, and selective use of orthotics could help reduce discomfort, prevent falls and fractures, and improve quality of life (95 [EL 1]). Lifestyle issues that could help prevent osteoporosis are summarized in Table 12.

\subsection{Evaluation for Risk Factors for Postmenopausal Osteoporosis}

Because the risk for osteoporosis-related fractures rises steeply in women beyond age 50 years, all postmenopausal women should undergo clinical assessment to identify risk factors for osteoporosis and fractures. This assessment should include the measures outlined in Table 13.

4.7.1. Spine Imaging-Vertebral fracture is the most common osteoporotic fracture and indicates a high risk for future fractures, even in patients whose bone density does not meet the $-2.5 \mathrm{~T}$-score threshold for the densitometric diagnosis of osteoporosis. Knowledge of vertebral fractures, therefore, may change an individual patient's diagnostic classification, estimated risk of future fractures, and clinical management. Most vertebral fractures, however, remain undetected unless specifically sought by radiologic or densitometric techniques (96 [EL 4]).

In patients with unexplained height loss, thoracic and lumbar spine radiography or vertebral fracture assessment by DXA is indicated if knowledge of vertebral fractures would alter clinical management (Grade B; BEL 2). Although height loss may occur for reasons other than vertebral fracture (97 [EL 2]), there is evidence to support radiography for measured 
height loss $>2 \mathrm{~cm}$ ( $>0.8$ inch) (98 [EL 2]) or historical height loss (loss from patient's recalled maximal height) $>4$ to $6 \mathrm{~cm}$ (>1.5 to 2.4 inches) (99 [EL 2]). Although these thresholds of height loss have $>90 \%$ specificity, the sensitivity for detecting prevalent vertebral fractures is low. Other indications for vertebral imaging include kyphosis and systemic glucocorticoid therapy, both of which are associated with increased vertebral fracture risk. Radiographic studies are also indicated for the evaluation of acute back pain suggestive of compression fracture. The sensitivity and reliability of standard radiography to assess BMD are poor, and in the absence of vertebral fractures, this technique cannot be used to diagnose osteoporosis.

4.7.2. BMD Measurement-In women who are at risk for postmenopausal osteoporosis, there are several potential uses of BMD measurements, as shown in Table 14.

4.7.2.1. Measurement techniques: DXA of the lumbar spine and proximal femur (hip) provides accurate and reproducible BMD measurements at important sites of osteoporosisassociated fracture (Grade B; BEL 1). Optimally, both hips should be measured during the initial visit to prevent misclassification that may result if only one hip is measured and to have a baseline for both hips in case a fracture or replacement occurs in one hip. These central sites are also more likely than peripheral sites to show a response to treatment and are preferred for baseline and serial measurements. The most reliable comparative results are obtained when the same instrument and, ideally, the same technologist are used for serial measurements.

For BMD measurement, several other techniques are available, including quantitative computed tomography for measurement of both central and peripheral sites, quantitative ultrasonometry, radiographic absorptiometry, and single-energy x-ray absorptiometry. Of note, the diagnostic criteria established by WHO and recommended by AACE apply only to central DXA measurements (specifically, lumbar spine, femoral neck, and total hip) and to DXA of the $1 / 3(33 \%)$ radius site. Thus, other technologies cannot be used to diagnose osteoporosis but may be used to assess fracture risk.

4.7.2.2. Bone density reports: Bone density results are reported as grams of mineral per square centimeter of projected bone area but are also expressed as T-scores and Z-scores. The T-score represents the number of SDs from the normal young adult mean values, whereas the Z-score represents the number of SDs from the normal mean value for age-, race-, and sex-matched control subjects. Only T-scores are used for diagnosis. Low Z-scores may suggest a secondary cause of osteoporosis, but normal Z-scores do not rule out the possibility of underlying disorders.

4.7.2.3. Measurement sites: Diagnostic criteria, therapeutic studies, cost analyses, and costeffectiveness data have been based primarily on DXA measurements of the total hip, femoral neck, or total lumbar spine (or some combination of these sites), which are the preferred measurement sites (Grade B; BEL 3). Use of other subregions within the proximal femur or of an individual vertebra has not been validated and is not recommended. 
Peripheral measurements can identify patients at increased risk for fracture; however, the WHO criteria for the densitometric diagnosis of low BMD (osteopenia) and osteoporosis do not apply to T-scores from peripheral devices. Currently, work is under way to define the appropriate diagnostic thresholds for peripheral measurement devices. In the interim, peripheral measurements should be limited to the assessment of fracture risk.

4.7.2.4. Role in diagnosis and clinical decision making: A clinical diagnosis of osteoporosis and decision to initiate pharmacologic therapy can be made without BMD testing in postmenopausal women who have fragility fractures of the hip or spine.

Nevertheless, BMD measurement is useful in these patients to quantify fracture risk and to establish a baseline for monitoring the response to treatment.

For women without prior fractures (in the absence of major trauma), BMD is the single predictor of future fracture risk (for every 1-SD decrease in age-adjusted BMD, the relative risk of fracture increases 1.6-fold to 2.6-fold) (47 [EL 2]). The relationship between bone density and fracture risk, however, is a continuum, without a clear "fracture threshold." WHO has defined T-score criteria for the classification of osteoporosis and low bone mass (osteopenia) (Table 3) on the basis of DXA measurements (Grade C; BEL 2). These criteria are useful for classification and risk stratification in individual patients, epidemiologic studies, and therapeutic trial design, but they are not intended as treatment thresholds. Although there is good evidence that the risk for fractures is sufficiently high in most postmenopausal women with osteoporosis (T-scores $\leq 2.5$ ) to merit pharmacologic intervention, cost-effective management of women with osteopenia (T-scores between -1.0 and -2.5) is less clear-cut. Although their overall rate of fractures is lower than that of patients with osteoporosis, more than $50 \%$ of fragility fractures occur in these patients with low bone mass. In order to identify those patients who are most likely to sustain a fracture, BMD results must be used in combination with other clinical risk factors for osteoporosisrelated fractures (Table 8) for accurate assessment of fracture risk and appropriate treatment decisions. The FRAX tool integrates the contribution of BMD and other clinical risk factors and calculates an individual patient's absolute probability of fracture during a period of 10 years. It is now recommended that treatment decisions include consideration of fracture probability.

4.7.2.5. Indications: BMD testing is useful for screening people at high risk for osteoporosis (for example, postmenopausal women), for disease management in patients with hyperparathyroidism and other disorders or those taking medications (such as glucocorticoids) associated with bone loss (Table 4), if evidence of bone loss would result in modification of therapy, and for monitoring of pharmacologic therapy with bone-active agents. A list of indications for BMD testing is shown in Table 15.

The cost-effectiveness of BMD testing and its benefits to society are controversial (100 [EL 1]). Clinicians, politicians, patients, industry, and third-party payers all have different perspectives on the indications for and timing of BMD measurements. The current recommendations are intended to outline reasonable use of this technology within the context of the endocrine specialty practice. Because universal BMD testing is not costeffective, AACE recommendations for screening include women 65 years of age or older 
(Grade B; BEL 3) and younger postmenopausal women at increased risk based on fracture risk analysis (Grade C; BEL 2). Indications for screening men for osteoporosis are outside the scope of these guidelines.

\subsection{Medical Evaluation for Postmenopausal Osteoporosis}

A comprehensive medical evaluation is indicated in all women with postmenopausal osteoporosis to identify coexisting medical conditions that cause or contribute to bone loss (Grade B; BEL 2). Some of these disorders may be asymptomatic and require laboratory testing for detection. Some causes of osteoporosis in adults are summarized in Table 9.

Because of the high prevalence of secondary osteoporosis, even in apparently healthy postmenopausal women, some laboratory testing should be considered for all women with osteoporosis. In a retrospective study, the laboratory tests itemized in Table 16 were found to detect more than $90 \%$ of disorders in postmenopausal women with osteoporosis who were otherwise asymptomatic (101 [EL 2], 102 [EL 4]). If the medical history, physical findings, or laboratory test results suggest the presence of secondary osteoporosis, additional laboratory evaluation is warranted and may include (but is not limited to) the tests listed in Table 17.

\subsection{Biochemical Markers of Bone Turnover}

Biochemical markers of bone turnover provide a dynamic assessment of skeletal activity and are useful modalities for skeletal assessment. Although they cannot be used to diagnose osteoporosis, elevated levels have been shown to predict more rapid rates of bone loss in groups of patients (103 [EL 1]) and to be associated with increased fracture risk independent of BMD at menopause and in elderly women (104 [EL 2]). In addition, these markers respond quickly to therapeutic intervention, and changes in markers have been associated with bone response to therapy and fracture risk reduction (105 [EL 1]). Their use in clinical practice, however, is limited by high in vivo and assay variability (resorption markers), poor predictive ability in individual patients, and lack of evidence-based thresholds for clinical decision making.

Nevertheless, biochemical markers of bone turnover may be useful in certain situations, including for assessment of fracture risk in elderly patients when the finding of elevated levels would influence the decision to begin pharmacotherapy, as an early indicator of therapeutic response to anabolic or antiresorptive therapy or in the laboratory evaluation of patients losing BMD despite antiresorptive therapy, and for assessment of medication compliance, drug absorption, or therapeutic efficacy (Grade C; BEL 1).

\subsection{Treatment of Osteoporosis}

4.10.1. Goals of Treatment-The therapeutic goals in patients with osteoporosis are as follows:

- To prevent fractures by improving bone strength and reducing the risk of falling and injury

- To relieve symptoms of fractures and skeletal deformity 
- To maximize physical function

Achieving these goals depends on commitment to therapy from the patient and the healthcare provider and the potential for the chosen therapy to yield results. Measures to achieve these goals are shown in Table 18.

4.10.2. Candidates for Pharmacologic Treatment-AACE has endorsed the 2008 National Osteoporosis Foundation Clinician's Guide to Prevention and Treatment of Osteoporosis (106 [EL 4]). The Guide recommends pharmacologic treatment for postmenopausal women with the following:

- A hip or spine fracture (either clinical spine fracture or radiographic fracture) (Grade A; BEL 1)

- A T-score of -2.5 or below at the spine, femoral neck, or total hip (Grade A; BEL 1)

- A T-score between -1.0 and -2.5 at high 10-year risk of fracture with use of the US-adapted FRAX tool provided by WHO at www.shef.ac.uk/FRAX, where treatment is considered cost-effective if the 10 -year risk is $3 \%$ or more for hip fracture or $20 \%$ or more for "major" osteoporosis-related fracture (humerus, forearm, hip, or clinical vertebral fracture) (Grade A; BEL 2). FRAX has been described more completely earlier (see section 4.5).

\subsection{Pharmacologic Agents for Treatment of Osteoporosis}

AACE and the American College of Endocrinology recommend the following pharmacologic agents when pharmacotherapy is indicated:

- First priority: agents approved by the US Food and Drug Administration (FDA) for the prevention or treatment (or both) of osteoporosis

- Second priority: agents not approved by the FDA but for which level 1 or level 2 evidence for efficacy and safety is available. These agents may be appropriate for patients who are unable to take approved agents or who have complex and extenuating medical problems that preclude the effective use of approved agents.

The manufacturer's prescribing information should be consulted for risks and benefits of any medication that is prescribed.

Adherence and persistence are poor for osteoporosis therapies (107 [EL 2], 108 [EL 1]), as is the case for other "silent" conditions such as hypertension and hyperlipidemia. Special efforts should be made to explain to the patient about the need for therapy and the expectations, as well as to schedule periodic follow-up to ensure that the medication is still being used correctly and appropriately.

Agents approved by the FDA for prevention or treatment of osteoporosis are shown in Table 19. They include (in alphabetical order) bisphosphonates (alendronate, ibandronate, risedronate, and zoledronic acid), calcitonin, denosumab, estrogen, raloxifene, and teriparatide. All these drugs act by reducing bone resorption, except for teriparatide, which 
has anabolic effects on bone. Because changes in intermediate end points, such as BMD and bone turnover markers, do not correlate strongly with fracture risk reduction, agents should be chosen on the basis of their proven efficacy in reducing fracture risk.

Level 1 evidence for efficacy in reducing the risk of new vertebral fractures is available for all the agents approved for treatment of osteoporosis (alendronate, ibandronate, risedronate, zoledronic acid, calcitonin, denosumab, raloxifene, and teriparatide). Prospective trials have demonstrated the effectiveness of alendronate, risedronate, zoledronic acid, denosumab, and teriparatide in reducing the risk of nonvertebral fractures (EL 1); only alendronate, risedronate, zoledronic acid, and denosumab have been shown to reduce the risk of hip fractures in prospective controlled osteoporosis trials (EL 1). AACE recommends alendronate, risedronate, zoledronic acid, or denosumab as first-line agents (Grade A; BEL 1), ibandronate as a second-line agent (Grade A; BEL 1), raloxifene as a second- or thirdline agent (Grade A; BEL 1), and calcitonin as the last-line agent (Grade C; BEL 2). Teriparatide has been shown to reduce the risk of vertebral and nonvertebral fractures. It is recommended for patients with very high fracture risk or those in whom bisphosphonate therapy has been ineffective (Grade A; BEL 1). The evidence for fracture risk reduction at categorical sites is summarized in Table 20.

\subsection{Bisphosphonates}

Bisphosphonates are the most widely used drugs for treatment of osteoporosis. Orally administered bisphosphonates must be taken after a prolonged fast (usually the first thing in the morning) and washed down with a full glass of water, not just a sip (to minimize the chance that the tablet will stick in the esophagus). Nothing other than water should be taken for 30 minutes (for alendronate and risedronate) or 60 minutes (for ibandronate). Under ideal conditions, the absorption of orally administered bisphosphonates is less than $1 \%$. Taking any bisphosphonate in conjunction with food, any beverage other than plain water, or certain other medications or ingesting it within 2 hours after a meal may substantially reduce or abolish the absorption of the drug.

Contraindications to bisphosphonate therapy include hypersensitivity or hypocalcemia. Bisphosphonates should be used with caution, if at all, in patients with reduced kidney function (glomerular filtration rate below $30 \mathrm{~mL} / \mathrm{min}$ for risedronate and ibandronate or below $35 \mathrm{~mL} / \mathrm{min}$ for alendronate and zoledronate) (109). There is some evidence that alendronate and risedronate are safe and effective in patients with moderate reduction of renal function (107 [EL 2], 108 [EL 1]).

Orally administered bisphosphonates should be used with caution in patients with active upper GI disease, inability to follow the dosing regimen for oral use (that is, inability to remain upright for 30 to 60 minutes), or presence of anatomic or functional esophageal abnormalities that might delay transit of the tablet (for example, achalasia or stricture).

Intravenous administration of nitrogen-containing bisphosphonates, such as ibandronate and zoledronate, causes acute phase reactions in up to $30 \%$ to $40 \%$ of patients receiving their first dose (110 [EL 3]). These reactions are characterized by fever and muscle aches lasting 
several days. Acetaminophen given at the time of treatment may reduce the likelihood of these reactions and can also be given to treat the symptoms.

Although rapid administration of nitrogen-containing bisphosphonates may interfere with kidney function (111-113 [EL 3]), this adverse effect has not been observed with intravenously administered ibandronate or zoledronic acid given to patients with normal renal function in accordance with appropriate dosing instructions (114 [EL 3]).

Some patients treated with an orally or intravenously administered bisphosphonate experience bone, joint, or muscle complaints that may be severe (115 [EL 3]) but that usually resolve when use of the drug is discontinued. Osteonecrosis of the jaw (ONJ) has been associated rarely with bisphosphonate therapy for osteoporosis (116-118 [EL 4]); risk factors include dental pathologic conditions, invasive dental procedures, or poor dental hygiene.

Another rare event that may be associated with alendronate is a subtrochanteric fracture (119 [EL 1], 120 [EL 2]). Occasionally, such fractures are described as "chalk stick" because of their radiologic appearance. They occur after minimal or no trauma. Sometimes the patient complains of leg pain preceding the event. A sclerotic appearance to the subtrochanteric region may be seen radiologically. It has been claimed that these patients may have very low bone turnover, although this point has not been rigorously substantiated. Whether a direct etiologic relationship exists between ONJ or these femoral fractures and the use of bisphosphonates is not clear (121 [EL 4], 122 [EL 3]). Evidence for atypical femoral shaft fractures has recently been reviewed by a task force of the American Society for Bone and Mineral Research (123).

The possible association between orally administered bisphosphonates and esophageal cancer has been explored. One study suggested no increased risk (124 [EL 2]), and one suggested that risk was increased with long-term use but small in absolute terms-from 1 case per 1,000 in untreated subjects to 2 cases per 1,000 with bisphosphonate use of 5 years or more (125 [EL 2]).

Atrial fibrillation as a serious adverse event was noted in the zoledronic acid Pivotal Fracture Trial (126 [EL 1]) but was not seen in other trials of zoledronic acid or other bisphosphonates and is thought by the FDA to be a chance finding (see http://www.fda.gov/ Drugs/DrugSafety/PostmarketDrugSafetyInformationforPatientsandProviders/ ucm101551.htm).

\subsubsection{Alendronate}

4.12.1.1. Role in clinical practice: Alendronate is approved by the FDA for prevention and treatment of postmenopausal osteoporosis, treatment of glucocorticoid-induced osteoporosis, and treatment of osteoporosis in men.

4.12.1.2. Available forms and recommended dosing: Initially, $10 \mathrm{mg}$ daily of alendronate was approved for treatment of postmenopausal osteoporosis, and $5 \mathrm{mg}$ daily was approved for prevention of bone loss in recently menopausal women. Subsequently, $70 \mathrm{mg}$ weekly of 
alendronate was approved for treatment of postmenopausal osteoporosis, and $35 \mathrm{mg}$ weekly was approved for prevention of bone loss. Alendronate $5 \mathrm{mg}$ daily is the approved dosage for treatment of corticosteroid-induced osteoporosis in men and estrogen-replete women, and $10 \mathrm{mg}$ daily is the approved dosage for treatment of corticosteroid-induced osteoporosis in estrogen-deficient women. Alendronate dosages of $10 \mathrm{mg}$ daily and $70 \mathrm{mg}$ weekly are approved for treatment of osteoporosis in men (127).

Alendronate is supplied in 5-mg and 10-mg tablets for daily administration and as 35-mg and 70-mg tablets, as 70-mg liquid unit dose, and as Fosamax Plus D (70 mg of alendronate plus 2,800 IU or 5,600 IU of vitamin D), all for once-weekly oral administration.

Alendronate is also now available in generic tablets for both daily and weekly dosing. Many physicians are unsure about the tolerability and efficacy of generic alendronate, but to the time of this writing, there have been no publications to alleviate or address these concerns for generic preparations available in the US.

4.12.1.3. Efficacy: Alendronate has been shown to reduce the risk of fractures of the spine (128 [EL 1], 129 [EL 1]), hip (128[EL 1]), and nonvertebral sites (130 [EL 2], 131 [EL 1]) in women with postmenopausal osteoporosis. Alendronate increases BMD at the spine and hip and prevents bone loss at the forearm (128 [EL 1], 129 [EL 1], 132 [EL 1]). Studies of up to 10 years' duration suggest continued efficacy (133 [EL 4], 134 [EL 1]).

4.12.1.4. Side effects: Studies of up to 13 years' duration indicate a good safety profile. In clinical trials, adverse events with alendronate did not differ from those with placebo (119 [EL 1], 121 [EL 4]). In clinical practice, however, upper GI symptoms such as heartburn, indigestion, substernal discomfort, and pain with swallowing may occur, and rare instances of esophageal erosion, ulceration, or bleeding have been described (122 [EL 3], 135 [EL 3], 136 [EL 3]). Most GI side effects are mild, but serious problems are seen in approximately 1 of 10,000 alendronate users (137 [EL 2]), often attributable to errors in patient selection or dosing. Weekly dosing is at least as well tolerated as daily dosing (138 [EL 1]) and may actually be better tolerated. If GI side effects occur, alendronate should be discontinued until symptoms are resolved, after which a bisphosphonate rechallenge could be considered with either alendronate or another orally administered bisphosphonate.

4.12.1.5. Duration of treatment: Alendronate has been studied in trials of up to 10 years' duration (133 [EL 4], 134 [EL 1]). Efficacy and safety beyond 10 years have not yet been established, but observational tracking is now up to 13 years. When alendronate is discontinued, no acceleration of bone loss relative to placebo has been noted, although slow but significant bone loss at the hip has been reported (135 [EL 3]). There is some suggestion that, after 4 to 5 years of therapy (and longer for those with severe osteoporosis), a drug holiday of 1 or 2 years could be offered without substantial loss of antifracture efficacy (134 [EL 1], 139 [EL 4]) (Grade B; BEL 1).

The concept of the drug holiday is based on persistent effects without active drug administration for a year or longer and the idea that some of the aforementioned adverse events may be related to bone turnover. When use of alendronate is discontinued for a year, bone turnover markers typically increase to about $25 \%$ to $30 \%$ higher than their values at the 
time the drug was stopped. When bone loss ensues, resumption of drug therapy is recommended.

Alendronate is also subject to class effect warnings discussed in section 4.12.

\subsubsection{Risedronate}

4.12.2.1. Role in clinical practice: Risedronate is approved by the FDA for prevention and treatment of postmenopausal osteoporosis, prevention and treatment of glucocorticoidinduced osteoporosis in men and women, and treatment of osteoporosis in men (140).

4.12.2.2. Available forms and recommended dosing: Risedronate was initially approved as a 5-mg daily dose for prevention of bone loss in recently menopausal women, treatment of postmenopausal osteoporosis, and prevention and treatment of corticosteroid-induced osteoporosis in men and women. Risedronate in doses of $35 \mathrm{mg}$ once weekly and $150 \mathrm{mg}$ once monthly is approved for treatment of postmenopausal osteoporosis. Risedronate is supplied as 5-, 35-, and 150-mg tablets and as Actonel with calcium, which consists of a blister pack containing 1 Actonel 35-mg tablet for weekly administration plus 6 calcium tablets to be taken daily (on the other days of the week) (140). The 75-mg tablets have been discontinued in the United States but may be available in other markets.

4.12.2.3. Efficacy: Risedronate has been shown to reduce the risk of fractures of the spine (141 [EL 1], 142 [EL 1]), hip (143 [EL 1]), and nonvertebral sites (141 [EL 1]) in women with postmenopausal osteoporosis. Risedronate increases BMD at the spine and hip and prevents bone loss at the forearm (141 [EL 1], 143 [EL 1]). Studies of up to 7 years' duration suggest continued efficacy (144 [EL 1], 145 [EL 2]).

4.12.2.4. Side effects: Studies of up to 9 years' duration indicate a good safety profile ( 145 [EL 2]). In clinical trials, adverse events with risedronate did not differ from those with placebo (141-143 [EL 1]). Side effects are generally mild and primarily affect the upper GI system. If GI side effects occur, risedronate should be discontinued until symptoms are resolved, after which a rechallenge with risedronate or other bisphosphonate should be considered.

Risedronate is also subject to class effect warnings discussed in section 4.12.

4.12.2.5. Duration of treatment: Risedronate has been studied in trials of up to 7 years' duration (145 [EL 2]). Efficacy and safety beyond 7 years have not yet been established, although clinical experience now extends to 9 years. When risedronate is discontinued, no acceleration of bone loss relative to placebo has been noted, although slow bone loss may occur (145 [EL 2], 146 [EL 1]). There is some suggestion that, after 3 years of therapy, a drug holiday of up to 1 year can be offered without significant loss of antifracture efficacy (146 [EL 1]). After 1 year of discontinuation, bone turnover markers essentially returned to baseline pretreatment levels (146 [EL 1]). Resuming risedronate therapy after 1 year is generally recommended (139 [EL 4]). 


\subsubsection{Ibandronate}

4.12.3.1. Role in clinical practice: Ibandronate is approved by the FDA for prevention and treatment of postmenopausal osteoporosis (147).

4.12.3.2. Available forms and recommended dosing: Ibandronate $2.5 \mathrm{mg}$ daily is the approved dose for prevention of bone loss in recently menopausal women and treatment of postmenopausal osteoporosis. Ibandronate $150 \mathrm{mg}$ once monthly is also approved for prevention and treatment of postmenopausal osteoporosis, and ibandronate $3 \mathrm{mg}$ given intravenously every third month is approved for treatment of postmenopausal osteoporosis (147).

Ibandronate is supplied as $2.5-\mathrm{mg}$ and $150-\mathrm{mg}$ tablets and as a 3-mg sterile solution for intravenous administration (147). Intravenous administration of ibandronate is by injection given during 15 to 30 seconds (147).

4.12.3.3. Efficacy: Ibandronate has been shown to reduce the risk of fractures of the spine in women with postmenopausal osteoporosis (148 [EL 1]). It has not been shown to reduce nonvertebral or hip fractures in prospective analysis. Ibandronate increases BMD at the spine and hip and prevents bone loss at the forearm (148 [EL 1], 149 [EL 1]).

4.12.3.4. Side effects: Studies of up to 3 years' duration indicate a good safety profile ( 148 [EL 1]). In clinical trials, adverse events with ibandronate did not differ from those with placebo (148 [EL 1]). Side effects are generally mild and primarily affect the upper GI system. As with the other bisphosphonates, upper GI side effects can occur with use of ibandronate. If they do occur, ibandronate should be discontinued until symptoms are resolved, after which a rechallenge should be considered.

Ibandronate is also subject to class effect warnings discussed in section 4.12.

4.12.3.5. Duration of treatment: Ibandronate has been studied in trials of up to 3 years' duration (148 [EL 1]). Efficacy and safety beyond 3 years have not yet been established. No published studies have addressed the discontinuation of ibandronate therapy.

\subsubsection{Zoledronic Acid}

4.12.4.1. Role in clinical practice: Zoledronic acid is approved by the FDA for prevention and treatment of postmenopausal osteoporosis, for men with osteoporosis, for patients after surgical repair of hip fracture, and for prevention and treatment of glucocorticoid-induced osteoporosis (150).

4.12.4.2. Available forms and recommended dosing: The approved dosage of zoledronic acid (Reclast) for all indications is $5 \mathrm{mg}$ given by intravenous infusion during a 15-minute period once yearly. It is important to distinguish this indication for zoledronic acid for osteoporosis from another dosing regimen of the same drug (that is, Zometa, $4 \mathrm{mg}$ administered intravenously each month) for patients with skeletal complications of malignancy. The branded product for osteoporosis is Reclast; the branded product for 
patients with a malignant condition is Zometa. Reclast and Zometa should not be used in the same patient.

Zoledronic acid is administered intravenously as a 5-mg infusion over a minimum of 15 minutes. For treatment of postmenopausal osteoporosis and osteoporosis in men as well as prevention and treatment of glucocorticoid-induced osteoporosis, it is given once yearly. For prevention of postmenopausal osteoporosis, the 5-mg dose is given once every 24 months. Before administration, patients should be appropriately hydrated, especially those receiving diuretic therapy. Serum calcium and creatinine concentrations should be monitored before administration of each dose (151 [EL 1]).

4.12.4.3. Efficacy: Zoledronic acid has been shown to reduce the risk of spine, nonvertebral, and hip fractures in women with postmenopausal osteoporosis (150), to reduce the rate of new clinical fractures in patients treated after surgical repair of hip fracture, and to reduce mortality in these patients. Zoledronic acid increases BMD at the spine and hip and prevents bone loss in men, postmenopausal women, and patients treated with glucocorticoids (126 [EL 1], 152 [EL 1]).

4.12.4.4. Side effects: Intravenous administration of zoledronic acid can cause acute phase reactions in up to $30 \%$ of patients receiving their first dose (126 [EL 1]). Subsequent doses or administration in patients who have previously been treated with alendronate is associated with a much smaller incidence (less than 2\%) (151 [EL 1]). These reactions are characterized by fever and muscle aches lasting several days. Acetaminophen given at the time of treatment may reduce the likelihood of this reaction, and it can also be given to treat the symptoms.

With zoledronic acid, most of the published literature has associated ONJ with the much higher dose that is used in patients with a malignant condition (132 [EL 1], 134 [EL 1], 153 [EL 1]). No published information suggests that $\mathrm{ONJ}$ is more common with intravenously administered zoledronic acid in the dose used to treat osteoporosis in comparison with orally administered bisphosphonates.

Zoledronic acid is also subject to class effect warnings discussed in section 4.12.

4.12.4.5. Duration of treatment: Zoledronic acid has been studied in trials of up to 3 years' duration (126 [EL 1]). Studies of efficacy and safety through 6 years have been completed but are not yet published. No published studies have addressed the discontinuation of zoledronic acid therapy.

\subsection{Raloxifene}

4.13.1. Role in Clinical Practice-Raloxifene is approved by the FDA for prevention and treatment of postmenopausal osteoporosis as well as for the reduction of risk of breast cancer in women with postmenopausal osteoporosis or at high risk of breast cancer (154). 
4.13.2. Available Forms and Recommended Dosing-The approved dosage of raloxifene for all indications is $60 \mathrm{mg}$ daily. It can be taken at any time of day, without regard for meals. Raloxifene is supplied as a 60-mg tablet (154).

4.13.3. Contraindications-Raloxifene is contraindicated in women of childbearing potential, those who have had venous thromboembolic disease, or those who are known to be hypersensitive to any component of raloxifene tablets (154).

4.13.4. Efficacy-Raloxifene has been shown to reduce the risk of fractures of the spine in women with postmenopausal osteoporosis (155 [EL 1]). Nonvertebral or hip fracture efficacy has not been demonstrated. It increases BMD in the spine and hip (153 [EL 1], 155 [EL 1]). Studies of up to 4 years' duration (156 [EL 1]) suggest continued efficacy.

4.13.5. Extraskeletal Effects-In studies in postmenopausal women, raloxifene reduced total cholesterol and low-density lipoprotein cholesterol fractions, but it had no apparent effect on high-density lipoprotein cholesterol (153 [EL 1], 155 [EL 1]). A large placebocontrolled study of raloxifene showed no beneficial or adverse cardiovascular effects or cerebrovascular events (that is, a neutral effect), but there was an overall increase in fatal strokes (157 [EL 1]).

In an osteoporosis trial with raloxifene, a significant reduction in breast cancer was seen (155 [EL 1]). This finding was confirmed in a larger trial of women at high risk of breast cancer (158 [EL 1]). Of note, raloxifene is not indicated for the treatment of invasive breast cancer, for reduction of the risk of recurrence of breast cancer, or for reduction of the risk of noninvasive breast cancer.

4.13.6. Side Effects-Raloxifene is associated with an approximate threefold increase in occurrence of venous thromboembolic diseases (similar to estrogen), although the absolute risk is low (157 [EL 1]). Other side effects include menopausal symptoms (for example, hot flashes and night sweats) and leg cramps (154).

4.13.7. Duration of Treatment-Efficacy has been determined for up to 4 years (156 [EL 1]), and safety has been determined for up to 8 years (159 [EL 1]). When use of raloxifene is stopped, the skeletal benefits appear to be lost fairly quickly (during the following 1 or 2 years).

\subsection{Teriparatide}

4.14.1. Role in Clinical Practice-Teriparatide—recombinant human $\mathrm{PTH}(1-34)$ - is approved by the FDA for treatment of women with postmenopausal osteoporosis who are at high risk of fracture or who have failed or been intolerant of previous osteoporosis therapy and to increase bone mass in men with idiopathic or hypogonadal osteoporosis who are at high risk of fracture or who have failed or been intolerant of previous osteoporosis therapy (160). Teriparatide is also approved for treatment of men and women with glucocorticoidinduced osteoporosis. It is prudent to measure the serum calcium, PTH, and 25(OH)D levels before treatment with teriparatide. 
4.14.2. Available Forms and Recommended Dosing-The approved dosage of teriparatide is $20 \mu \mathrm{g}$ once daily injected subcutaneously. Teriparatide is dispensed in a glass cartridge that is preassembled into a disposable multiple-dose pen syringe device designed to provide 28 doses (160).

4.14.3. Efficacy-Teriparatide has been shown to reduce the risk of vertebral and nonvertebral fractures in women with postmenopausal osteoporosis (161 [EL 1]). Teriparatide increases BMD in the spine dramatically but has little effect on BMD in the hip or forearm (161 [EL 1]). Patients who lose BMD in the hip with teriparatide treatment are still protected against vertebral fracture (162 [EL 2]).

4.14.4. Contraindications-Teriparatide has a "black box" warning because of the occurrence of osteosarcomas in rats treated with very high doses of teriparatide (3 to 58 times higher than the human equivalent dose) starting at 2 weeks of age and continued for their lifetimes (approximately 75 human-year equivalents) (163 [EL 1]). Subsequent studies in the same strain of rats showed no development of malignant bone tumors with use of doses of teriparatide up to 3 times higher than the human equivalent dose (164 [EL 1]). Because teriparatide caused an increased incidence of osteosarcomas in rats, it is contraindicated in patients at increased risk of osteosarcoma (those with Paget disease of bone, open epiphyses, a history of irradiation involving the skeleton, or an unexplained elevation of alkaline phosphatase level of skeletal origin) (160). The incidence of osteosarcomas in women 50 years old or older is approximately 1 in 250,000. The actual incidence of osteosarcoma in users of teriparatide is unknown; there are rare reports, consistent with the background incidence (165 [EL 4], 166 [EL 3]). Teriparatide should also not be administered to patients with primary or any form of secondary untreated or unresolved hyperparathyroidism (160).

4.14.5. Side Effects-Side effects of teriparatide have been mild and transient and include nausea, orthostatic hypotension (which usually does not necessitate discontinuation of the drug, occurs in association with the first few doses, and responds to assumption of a recumbent posture), and leg cramps. Hypercalcemia, usually mild, asymptomatic, and transient, has been observed but is not common (160).

4.14.6. Duration of Treatment-Efficacy and safety of teriparatide have been assessed for a period of 2 years and are currently unknown thereafter. Treatment with teriparatide is not recommended to exceed 2 years (160). When use of teriparatide is stopped, bone density declines quickly during the following year, although fracture reduction may persist for 1 or 2 years (167 [EL 2]). Use of alendronate after teriparatide therapy prevents this loss and in some cases will be associated with a further increase in BMD (168 [EL 1]).

\subsection{Calcitonin}

4.15.1. Role in Clinical Practice-Injectable and nasal spray salmon calcitonin are approved by the FDA for treatment of postmenopausal osteoporosis $(169,170)$. 
4.15.2. Available Forms and Recommended Dosing-The approved dosage of injectable calcitonin for treatment of postmenopausal osteoporosis is $100 \mathrm{IU}$ daily given subcutaneously or intramuscularly. The approved dose of nasal spray calcitonin is 200 IU (1 spray) daily. Injectable salmon calcitonin is available in a sterile solution. Intranasally administered calcitonin is available in a spray bottle that delivers $200 \mathrm{IU}$ per spray $(169,170)$.

4.15.3. Contraindications-The main contraindication to use of calcitonin is hypersensitivity $(169,170)$. For patients with suspected sensitivity to the drug, skin testing is recommended before treatment.

4.15.4. Efficacy-There are no published studies with injectable calcitonin that show antifracture efficacy. Nasal spray salmon calcitonin (200 IU daily) has been shown to reduce the risk of new vertebral fractures in women with postmenopausal osteoporosis, but neither a lower dose (100 IU daily) nor a higher dose (400 IU daily) was effective (171 [EL 1]). Nonvertebral and hip fracture efficacy has not been demonstrated. Calcitonin produces a minimal increase in BMD in the spine in women $>5$ years after onset of menopause but does not increase BMD at sites other than the spine (171 [EL 1]).

4.15.5. Side Effects-Studies of up to 5 years' duration indicate a good safety profile (171 [EL 1]). Common side effects of parenterally administered calcitonin include nausea, local inflammatory reactions at the injection site, and vasomotor symptoms including sweating and flushing. The most common side effect of nasally administered calcitonin is nasal discomfort, including rhinitis, irritation of the nasal mucosa, and occasional epistaxis. Use of calcitonin with either route of administration is well tolerated $(169,170)$.

4.15.6. Duration of Treatment-The optimal duration of treatment with calcitonin is unknown. Safety and efficacy data are available through 5 years (171 [EL 1]). When use of calcitonin is stopped, the skeletal benefits are lost fairly quickly (during the subsequent 1 or 2 years).

\subsection{Denosumab}

4.16.1. Role in Clinical Practice-Denosumab is a fully human monoclonal antibody against RANKL that reduces the amount of RANKL in the bone microenvironment, reduces the differentiation of precursor cells into mature osteoclasts, and decreases the function and survival of activated osteoclasts. Denosumab is approved by the FDA for treatment of postmenopausal women at high risk of fracture, defined as having a history of osteoporotic fracture or multiple risk factors for fracture, or patients who have failed or are intolerant of other available osteoporosis therapy.

4.16.2. Available Forms and Recommended Dosing-The approved dosage of denosumab is $60 \mathrm{mg}$ by subcutaneous injection given once every 6 months. It is available in prefilled syringes or single-dose vials. 
4.16.3. Efficacy-Denosumab has been shown to reduce the risk of fractures of the spine, hip, and nonvertebral sites (172 [EL 1]) in women with postmenopausal osteoporosis.

Denosumab increases BMD at the spine, hip, and forearm (172 [EL 1]). Studies of up to 3 years' duration suggest continued efficacy (172 [EL 1]).

4.16.4. Side Effects-Studies of up to 6 years' duration indicate a good safety profile (172-174 [EL 1]). Hypocalcemia must be corrected before initiation of therapy. Serious infections, including skin infections, may occur. Patients should be advised to seek prompt medical attention if signs or symptoms of infection, including cellulitis, develop. Dermatitis, rashes, and eczema have been reported; consider discontinuing the use of denosumab if severe symptoms develop. In patients treated with denosumab, ONJ has been reported. Suppression of bone turnover of uncertain clinical significance has been demonstrated.

4.16.5. Duration of Treatment-Denosumab has been studied in trials of up to 6 years' duration (174 [EL 1]). Efficacy and safety beyond 6 years have not yet been established, but clinical trials are likely to be extended through 10 years. When treatment with denosumab was stopped after 2 years, BMD decreased to baseline values and bone turnover markers increased to values above baseline by 12 months after discontinuation (174 [EL 1]).

\subsection{Estrogen and Menopausal Hormone Therapy}

4.17.1. Role in Clinical Practice—Although once considered the "treatment of choice" for postmenopausal osteoporosis, estrogen was never specifically approved for treatment of osteoporosis. It is approved by the FDA for prevention of postmenopausal osteoporosis with the added caveat, "when prescribing solely for the prevention of postmenopausal osteoporosis, therapy should only be considered for women at significant risk of osteoporosis and for whom non-estrogen medications are not considered to be appropriate" (175).

4.17.2. Available Forms and Recommended Dosing-Several different formulations of estrogen are available (for example, estradiol, conjugated equine estrogens, esterified estrogens) for administration by oral and transdermal routes. The optimal dose and route of administration for skeletal effects are not known. When estrogen is prescribed for a patient who still has her uterus, a progestin should also be used, either daily or cyclically, to protect against endometrial stimulation.

4.17.3. Efficacy-Conjugated equine estrogen ( $0.625 \mathrm{mg}$ daily), with or without medroxyprogesterone acetate, has been shown to reduce the risk of fractures of the spine, hip, and nonvertebral sites in postmenopausal women (176 [EL 1], 177 [EL 1]). Estrogen increases BMD in the spine, hip, and forearm (178-180 [EL 1]).

4.17.4. Extraskeletal Effects-There has been considerable controversy regarding the extraskeletal effects of estrogen, particularly with regard to cardiovascular disease and breast cancer. The WHI trial of combination estrogen plus progestin therapy suggested an increased risk of thromboembolic, cerebrovascular, and cardiovascular events, as well as breast cancer, although the risk-to-benefit ratio was close to neutral (181 [EL 1]). In the 
WHI estrogen-only trial, there was no increased risk of cardiovascular events or breast cancer but no overall benefit either (182 [EL 1]).

4.17.5. Side Effects-In women with an intact uterus, unopposed estrogen therapy is associated with an increased risk of endometrial hyperplasia and carcinoma. When appropriate dosages of progestin are used along with estrogen, this added risk is eliminated. When estrogen therapy is initiated, particularly continuous estrogen-progestin regimens, irregular vaginal bleeding can occur in women with an intact uterus. Vaginal spotting may diminish with time. Estrogen increases the risk of cholelithiasis twofold. Fluid retention, mastalgia, abdominal pain, and headache may occur but may be ameliorated with use of a lower dose. There is an approximate 3 -fold increased risk of venous thromboembolism in women who use estrogen in comparison with nonusers. The absolute risk is small (approximately 3 in 1,000 to 3 in 10,000). In some women with sensitivity, estrogen therapy can be associated with dramatic increases in serum triglyceride levels.

4.17.6. Contraindications-The following are contraindications to estrogen or combination estrogen-progestin therapy (175):

- Known or suspected pregnancy

- Known or suspected cancer of the breast

- Known or suspected estrogen-dependent neoplasm

- Undiagnosed abnormal genital bleeding

- Active thrombophlebitis or thromboembolic disorders or a history of thromboembolic disease

- Hypersensitivity to the hormones

4.17.7. Duration of Treatment-The main indication for the use of estrogen is for relief of menopausal symptoms. When given for this indication, estrogen should be administered in the lowest dose necessary to relieve symptoms and for the shortest duration possible. When use of estrogen is stopped, the antifracture benefits are lost fairly quickly (during the subsequent 1 or 2 years). Bone density may decrease as much as $5 \%$ during the first year after discontinuation of estrogen therapy (183 [EL 1]).

\subsection{Concomitant Use of Therapeutic Agents}

There are no studies showing that combination treatment with 2 or more osteoporosis drugs has a greater effect on fracture reduction than treatment with a single agent (184 [EL 4]). Modest additive effects on BMD and bone turnover have been observed with combinations of 2 antiresorptive agents. The combined use of an antiresorptive drug and teriparatide or PTH may alter the BMD and bone turnover response, depending on which antiresorptive agent is used (185 [EL 1]). Combination therapy substantially increases the cost and probably increases the potential for side effects. Until the effect of combination therapy on fracture risk is better understood, however, AACE does not recommend concomitant use of these agents for prevention or treatment of postmenopausal osteoporosis (Grade B; BEL 2). 


\subsection{Sequential Use of Therapeutic Agents}

Sequential use of therapeutic interventions can be considered in the context of the 2 major classes of drugs that are available - the antiresorptive and the anabolic agents. In patients who are being considered for anabolic therapy after antiresorptive treatment, experimental support exists for the idea that the more potent the antiresorptive agent in suppressing bone turnover, the more sluggish the initial response to anabolic therapy (186 [EL 1], 187). The rationale for using an antiresorptive agent after anabolic therapy is based, in part, on the limited period that anabolic therapy with teriparatide is used and, in part, on observations that if antiresorptive therapy is not used after treatment with teriparatide is discontinued, bone loss is rapid (170).

\subsection{Nonapproved Therapies}

Etidronate and pamidronate are bisphosphonates that are available in the United States for specific indications but are not approved for prevention or treatment of osteoporosis. Because they are available, these agents can be used "off label" for patients with osteoporosis.

Etidronate is approved in the United States for treatment of Paget disease of bone (188). It has antifracture efficacy in women with postmenopausal osteoporosis (186 [EL 1]) and is approved for treatment of osteoporosis in several countries but not in the United States. It is an alternative for patients who have GI intolerance of approved orally administered bisphosphonates and who are not candidates for intravenous bisphosphonate treatment. Etidronate for osteoporosis is given in an intermittent cyclic regimen, $400 \mathrm{mg}$ daily for 14 days, with cycles repeated every 3 months (186 [EL 1]). Because it is not a nitrogencontaining bisphosphonate, etidronate does not irritate the esophageal mucosa.

Pamidronate is approved in the United States for treatment of Paget disease of bone and treatment of skeletal complications of malignant disease (187). Given by intravenous infusion, it may be useful for patients who cannot tolerate orally administered bisphosphonates or who may not absorb orally taken bisphosphonates because of GI disease. It has been shown to increase bone density in the spine and hip (EL 2), but there is no evidence for antifracture efficacy. A typical treatment schedule for pamidronate is a loading dose of $90 \mathrm{mg}$ followed by $30 \mathrm{mg}$ every third month (189 [EL 2]) given by intravenous infusion in dextrose or saline during a 2-hour period.

Agents not available in the United States but used in some countries include strontium ranelate, clodronate, tibolone, and the full-length molecule of $\mathrm{PTH}(1-84)$.

\subsection{BMD and Fracture Assessment for Monitoring Skeletal Status}

BMD testing may be done to determine whether or when to initiate treatment or to monitor the response to treatment. In untreated patients, the frequency of testing depends on the results of the initial test (for example, how close the patient is to an intervention threshold) and the likelihood of clinically significant bone loss. Age-related bone loss, which begins in the fifth decade of life, occurs at the rate of $0.5 \%$ to $1.0 \%$ per year (190 [EL 2]). Menopauserelated bone loss, which begins 3 to 5 years before the last menstrual period and continues 
for 3 to 5 years afterward, occurs at the rate of $1 \%$ to $2 \%$ per year (191 [EL 2]). Rapid bone loss (3\% to 5\% in a year) may occur with the initiation of glucocorticoid therapy (192 [EL 4]) or after discontinuing postmenopausal estrogen therapy. A "Bone Loss Calculator" is available through the International Society for Clinical Densitometry (ISCD) (www.iscd.org). One SD is about $10 \%$ of the young adult mean; thus, loss of $10 \%$ (which typically takes 10 to 20 years of age-related bone loss or 5 to 10 years of menopause-related bone loss) will result in a decrease of about $1 \mathrm{~T}$-score unit. The baseline result is also important. "Normal" and "osteopenia" are ranges, not points. Someone who has normal BMD with a T-score of +1.0 can afford to lose more bone than someone else who has normal BMD with a T-score of -0.9. For patients receiving treatment or approaching an intervention threshold, retesting every 1 to 2 years is often appropriate. For those who have borderline low results of BMD, retesting every 3 to 5 years is usually sufficient. Patients who are comfortably above an intervention threshold may not need to undergo reassessment for 5 or 10 years, or ever, unless there is some new indication.

Among patients receiving treatment, the goal of monitoring is to identify those who have substantial bone loss at clinically relevant sites: the posteroanterior (PA) spine or the hip (total hip or femoral neck). Stable or increasing BMD at these sites indicates a satisfactory response to treatment (193 [EL 4]). If BMD decreases considerably, patients should undergo assessment for noncompliance, secondary osteoporosis, or use of new medications that might cause bone loss.

To determine whether a difference in BMD is real or simply within the inherent variability of the measurement, testing facilities must calculate the "least significant change" (LSC) for relevant measurement sites to ascertain the magnitude of difference that represents a real change. This is determined by using a facility's regular technologist, patients, and device (194 [EL 4], 195 [EL 4]). The ISCD has established guidelines for determining the number of patients and repetitive scans needed to calculate the LSC (30 patients in duplicate or 15 patients in triplicate) (194 [EL 4], 195 [EL 4]). The LSC is usually set at the 95\% confidence limit for the change. The manufacturer's LSC should not be used because it does not account for differences in actual patients who will be tested and the performance and skill of the technologist. If serial studies show a difference in BMD that exceeds the LSC, the probability that the difference is real is greater than $95 \%$. Small changes, within the bounds of the LSC, should not be reported.

In addition to knowing the LSC, it is important to compare "apples with apples." Differences in regions of interest, local structural change, or artifacts may result in a "change" that does not reflect actual progression of bone loss or response to osteoporosis treatment. Before acceptance of a report of significant bone loss, the images and numeric results of the studies should be reviewed to assess comparability.

Changes in BMD are usually small ( $0.5 \%$ to $2.0 \%$ per year) and often close to the precision error of the measurement (1.0\% to $1.2 \%$ for the PA spine and $0.8 \%$ to $1.7 \%$ for the total hip). The definition of a "nonresponder" to therapy is complex, and the proportion of nonresponders for different therapies will vary depending on the definition. Furthermore, studies have shown that the change in BMD accounts for less than $20 \%$ of the fracture risk 
reduction after antiresorptive therapy (196 [EL 4], 197 [EL 1]). Finally, although it has been suggested that monitoring might improve patient compliance, nonadherence to therapy usually occurs early (after 6 to 7 months), before the second BMD measurement would be performed (198 [EL 3]).

Ideally, monitoring should occur at the same facility and with use of the same machine as for the previous DXA, and if possible, it should be performed by the same technologist and should involve the same regions of interest for both the spine and the hip (Grade B; BEL 2). The 1/3 (33\%) radius site is also acceptable. Other peripheral sites (for example, heel, finger, and tibia) cannot be used for monitoring. Most third-party payers and some Medicare carriers cover BMD testing repeated yearly; all Medicare carriers cover testing every 2 years. AACE recommends a repeated DXA at 1 to 2 years after initiation of therapy until bone density is stable. This testing pattern can be continued at every 2-year interval and reduced with evidence of persistent BMD stability (Grade B; BEL 2). Because sites rich in trabecular bone, such as the PA spine, are more metabolically active and likely to respond to therapy, an appreciable change is likely to occur earlier at the spine than at the hip.

Treatment failure may be defined as a substantial decrease in BMD or, alternatively, the occurrence of a fracture (Grade B; BEL 2). Some of the treated patients in clinical trials showed bone loss or sustained fractures (or both). It may be, however, that all patients benefit from treatment (if they lose bone with treatment, they may have lost more without it; if they sustain a fracture despite treatment, they may have had a fracture sooner or had multiple fractures without it) (193 [EL 4]). Nevertheless, it is reasonable that a patient with considerable bone loss or a new fragility fracture undergo assessment for compliance with medication, secondary causes of bone loss, or the addition of new medications or diseases that can cause bone loss (Grade B; BEL 2).

The skeletal status can also be examined by assessing the development or progression of asymptomatic vertebral fractures. This can be done by lateral radiography of the thoracic and lumbar spine. Alternatively, vertebral fracture assessment, a technique that can assess vertebral fractures with DXA technology, can often be done at the same time as DXA (199 [EL 2], 200 [EL 3], 201 [EL 2]). Both historical height loss and prospective height loss have been associated with a new vertebral fracture (98 [EL 2], 99 [EL 2]). The ISCD recommends screening for vertebral fractures in older patients with historical height loss $>1.6$ inches $(>4$ $\mathrm{cm})$ in women and $>2.4$ inches $(>6 \mathrm{~cm})$ in men, prospective height loss of 0.8 inch $(2 \mathrm{~cm})$ in women and 1.2 inches $(3 \mathrm{~cm})$ in men, or a self-reported nonvertebral fracture (202 [EL 4]).

Limited published data are available on the use of biochemical markers of bone turnover for follow-up in individual patients. Clinical trials have shown that early changes in bone turnover markers are associated with long-term changes in bone density in women taking antiresorptive (203 [EL 1]) or anabolic (204 [EL 1]) drugs. Significant reductions in bone turnover markers have also been associated with fracture reduction (197 [EL 1]).

Antiresorptive therapy is likely effective if bone turnover markers are at or below the median value for premenopausal women (Grade B; BEL 2). Use of a resorption marker, such as a fasting, second-voided urinary $\mathrm{N}$-telopeptide cross-linked collagen type 1 or a fasting morning serum C-telopeptide value, may be helpful in the evaluation of a nonresponder who 
has bone loss or fractures while receiving therapy or the identification of patients who have high bone turnover. An elevated level associated with high bone turnover in patients receiving therapy could represent poor compliance or the need for evaluation of a secondary cause of bone loss (Grade C; BEL 2).

\subsection{Surgical Treatment of Osteoporotic Fractures}

Fracture care is usually provided by orthopedic surgeons and is unlikely to be influenced by nonorthopedists. For vertebral fractures, vertebroplasty and kyphoplasty are in the purview of radiologists and neurosurgeons. These procedures are indicated for relief of pain; kyphoplasty has been suggested to provide at least partial reversal of the vertebral deformity. Two recently published comprehensive reviews discussed these treatments (205 [EL 4], 206 [EL 4]). Two sham-controlled studies concluded that vertebroplasty was without benefits (207 [EL 1], 208 [EL 1]), and a controlled study suggested that kyphoplasty was beneficial in restoring vertebral height (209 [EL 2]). Both procedures have been suggested to increase the risk of vertebral fractures in the adjacent vertebrae. Because of limitations to the published studies, the role for these surgical procedures is still uncertain.

\section{AACE Osteoporosis Task Force}

Chair

Nelson B. Watts, MD, FACP, MACE

Task Force Members

John P. Bilezikian, MD, MACE

Pauline M. Camacho, MD, FACE

Susan L. Greenspan, MD, FACP, FACE

Steven T. Harris, MD, FACE

Stephen F. Hodgson, MD, FACP, MACE

Michael Kleerekoper, MD, MACE

Marjorie M. Luckey, MD, FACE

Michael R. McClung, MD, FACP, FACE

Rachel Pessah Pollack, MD

Steven M. Petak, MD, JD, FACE, FCLM

Reviewers

Donald A. Bergman, MD, FACP, FACE 
Neil Binkley, MD

Paul D. Miller, MD, FACP

\section{DISCLOSURE}

Chair

Dr. Nelson B. Watts reports that he has received speaker honoraria from Amgen Inc., the International Society for Clinical Densitometry, Novartis AG, and Warner Chilcott; consultant honoraria from Amgen Inc., Arena Pharmaceuticals, Inc., Baxter, InteKrin Therapeutics Inc., Johnson \& Johnson Services, Inc., Medpace, Merck \& Co., Inc., NPS Pharmaceuticals, Orexigen Therapeutics, Inc., Pfizer Inc, sanofi-aventis U.S. LLC, Takeda, VIVUS, Inc., and Warner Chilcott; and research grant support through the University of Cincinnati Osteoporosis Center from Amgen Inc., Eli Lilly and Company, Merck \& Co., Inc., Novartis AG, and NPS Pharmaceuticals.

\section{Task Force Members}

Dr. John P. Bilezikian reports that he has received speaker honoraria from Amgen Inc., Eli Lilly and Company, and Novartis AG and consultant honoraria from Amgen Inc., Eli Lilly and Company, Merck \& Co., Inc., and Warner Chilcott.

Dr. Pauline M. Camacho reports that she has received research grant support for her role as principal investigator from Eli Lilly and Company and Procter \& Gamble.

Dr. Susan L. Greenspan reports that she has received consultant honoraria from Amgen Inc. and Merck \& Co., Inc. and research grant support for her role as principal investigator from the Alliance for Better Bone Health (Procter \& Gamble/sanofi-aventis U.S. LLC), Eli Lilly and Company, and Warner Chilcott.

Dr. Steven T. Harris reports that he has received speaker honoraria from Amgen Inc., Genentech, Inc., Gilead, GlaxoSmithKline plc, F. Hoffmann-La Roche Ltd, Eli Lilly and Company, Novartis AG, Procter \& Gamble, sanofi-aventis U.S. LLC, and Warner Chilcott and consultant honoraria from Amgen Inc., Gilead, GlaxoSmithKline plc, F. Hoffmann-La Roche Ltd, Eli Lilly and Company, Merck \& Co., Inc., and Novartis AG.

Dr. Stephen F. Hodgson reports that he does not have any relevant financial relationships with any commercial interests.

Dr. Michael Kleerekoper reports that he has received speaker honoraria from Amgen Inc. and Eli Lilly and Company and speaker and consultant honoraria from F. Hoffmann-La Roche Ltd Diagnostics.

Dr. Marjorie M. Luckey reports that she has received speaker honoraria and consultant fees from Amgen Inc. and Novartis AG. 
Dr. Michael R. McClung reports that he has received research grant support, consulting fees, and/or speakers' bureau honoraria from Amgen Inc., Eli Lilly and Company, Merck \& Co., Inc., Novartis AG, and Warner Chilcott.

Dr. Rachel Pessah Pollack reports that she does not have any relevant financial relationships with any commercial interests.

Dr. Steven M. Petak reports that he has received speaker honoraria from Amgen Inc. and the International Society for Clinical Densitometry.

\section{Reviewers}

Dr. Donald A. Bergman reports that he does not have any relevant financial relationships with any commercial interests.

Dr. Neil Binkley reports that he has received consultant honoraria from Amgen Inc., Merck \& Co. Inc., and Tarsa Therapeutics, Inc. and research grant support from Amgen Inc., Eli Lilly and Company, Merck \& Co., Inc., and Tarsa Therapeutics, Inc.

Dr. Paul D. Miller reports that he has received speaker, consultant, and advisory board honoraria from Amgen Inc., Genentech, Inc., GlaxoSmithKline plc, Eli Lilly and Company, Merck \& Co., Inc., Novartis AG, NPS Pharmaceuticals, and Warner Chilcott. He also reports that he has received scientific grants from Amgen Inc., F. Hoffmann-La Roche Ltd, Eli Lilly and Company, Merck \& Co., Inc., Novartis AG, and Warner Chilcott.

\section{Abbreviations}

$\begin{array}{ll}\text { AACE } & \text { American Association of Clinical Endocrinologists } \\ \text { BEL } & \text { "best evidence" level } \\ \text { BMD } & \text { bone mineral density } \\ \text { DXA } & \text { dual-energy x-ray absorptiometry } \\ \text { EL } & \text { evidence level } \\ \text { FDA } & \text { US Food and Drug Administration } \\ \text { GI } & \text { gastrointestinal } \\ \text { ISCD } & \text { International Society for Clinical Densitometry } \\ \text { LSC } & \text { least significant change } \\ \text { 25(OH)D } & \text { 25-hydroxyvitamin D } \\ \text { ONJ } & \text { osteonecrosis of the jaw } \\ \text { OPG } & \text { osteoprotegerin } \\ \text { PA } & \text { posteroanterior } \\ \text { PTH } & \text { parathyroid hormone }\end{array}$




$\begin{array}{ll}\text { R } & \text { recommendation } \\ \text { RANK } & \text { receptor activator of nuclear factor- } \kappa \beta \\ \text { RANKL } & \text { RANK ligand } \\ \text { SD } & \text { standard deviation } \\ \text { WHI } & \text { Women's Health Initiative } \\ \text { WHO } & \text { World Health Organization }\end{array}$

\section{REFERENCES}

Note: Reference sources are followed by an evidence level [EL] rating of 1,2,3, or 4 . The strongest evidence levels (EL $\mathbf{1}$ and EL 2) appear in red for easier recognition.

1. Mechanick JI, Camacho PM, Cobin RH, et al. American Association of Clinical Endocrinologists Clinical Practice Guidelines Subcommittee. American Association of Clinical Endocrinologists protocol for standardized production of clinical practice guidelines-2010 update. Endocr Pract. 2010; 16:270-283. [PubMed: 20350905]

2. Mechanick JI, Bergman DA, Braithwaite SS, Palumbo PJ. American Association of Clinical Endocrinologists Ad Hoc Task Force for Standardized Production of Clinical Practice Guidelines. American Association of Clinical Endocrinologists protocol for standardized production of clinical practice guidelines. Endocr Pract. 2004; 10:353-361. [published correction appears in Endocr Pract. 2008;14:802-803]. [PubMed: 15776523]

3. NIH Consensus Development Panel on Osteoporosis Prevention, Diagnosis, and Therapy. Osteoporosis prevention, diagnosis, and therapy. JAMA. 2001; 285:785-795. [PubMed: 11176917]

4. Kanis JA, Melton LJ III, Christiansen C, Johnston CC, Khaltaev N. The diagnosis of osteoporosis. J Bone Miner Res. 1994; 9:1137-1141. [EL 4]. [PubMed: 7976495]

5. Seeman E, Delmas PD. Bone quality - the material and structural basis of bone strength and fragility. N Engl J Med. 2006; 354:2250-2261. [EL 4]. [PubMed: 16723616]

6. National Osteoporosis Foundation. America's Bone Health: The State of Osteoporosis and Low Bone Mass in Our Nation. Washington, DC: National Osteoporosis Foundation; 2002. [EL 4]

7. Cummings SR, Melton LJ. Epidemiology and outcomes of osteoporotic fractures. Lancet. 2002; 359:1761-1767. [EL 3]. [PubMed: 12049882]

8. Looker AC, Orwoll ES, Johnston CC Jr, et al. Prevalence of low femoral bone density in older U.S. adults from NHANES III. J Bone Miner Res. 1997; 12:1761-1768. [EL 3]. [PubMed: 9383679]

9. Faulkner KG, von Stetten E, Miller P. Discordance in patient classification using T-scores. J Clin Densitom. 1999; 2:343-350. [EL 3]. [PubMed: 10548828]

10. Melton LJ III, Lane AW, Cooper C, Eastell R, O’Fallon WM, Riggs BL. Prevalence and incidence of vertebral deformities. Osteoporos Int. 1993; 3:113-119. [EL 3]. [PubMed: 8481586]

11. Burge R, Dawson-Hughes B, Solomon DH, Wong JB, King A, Tosteson A. Incidence and economic burden of osteoporosis-related fractures in the United States, 2005-2025. J Bone Miner Res. 2007; 22:465-475. [EL 3]. [PubMed: 17144789]

12. Rosamond W, Flegal K, Friday G, et al. American Heart Association Statistics Committee and Stroke Statistics Subcommittee. Heart disease and stroke statistics-2007 update: a report from the American Heart Association Statistics Committee and Stroke Statistics Subcommittee. Circulation. 2007; 115:e69-e171. [published corrections appear in Circulation. 2007;115:e172 and 2010;122:e9]. [EL 3]. [PubMed: 17194875]

13. American Cancer Society. Cancer Facts and Figures 2006. Atlanta, GA: American Cancer Society; 2006. http://www.cancer.org/acs/groups/content/@nho/documents/document/ caff2006pwsecuredpdf.pdf. [EL 3] [Accessed for verification November 7, 2010] 
14. Forsén L, Sogaard AJ, Meyer HE, Edna T, Kopjar B. Survival after hip fracture: short- and longterm excess mortality according to age and gender. Osteoporos Int. 1999; 10:73-78. [EL 2]. [PubMed: 10501783]

15. Poór G, Atkinson EJ, Lewallen DG, O’Fallon WM, Melton LJ III. Age-related hip fractures in men: clinical spectrum and short-term outcomes. Osteoporos Int. 1995; 5:419-426. [EL 2]. [PubMed: 8695962]

16. Gehlbach SH, Burge RT, Puleo E, Klar J. Hospital care of osteoporosis-related vertebral fractures. Osteoporos Int. 2003; 14:53-60. [EL 3]. [PubMed: 12577185]

17. Ray NF, Chan JK, Thamer M, Melton LJ III. Medical expenditures for the treatment of osteoporotic fractures in the United States in 1995: report from the National Osteoporosis Foundation. J Bone Miner Res. 1997; 12:24-35. [EL 3]. [PubMed: 9240722]

18. Greendale, GA.; Barrett-Connor, E. Outcomes of osteoporotic fracture. In: Marcus, R.; Feldman, D.; Kelsey, J., editors. Osteoporosis. San Diego, CA: Academic Press; 2001. p. 819-829.[EL 3]

19. Melton LJ III, Kearns AE, Atkinson EJ, et al. Secular trends in hip fracture incidence and recurrence. Osteoporos Int. 2009; 20:687-694. [EL 3]. [PubMed: 18797813]

20. Centers for Disease Control and Prevention (CDC). Fatalities and injuries from falls among older adults-United States, 1993-2003 and 2001-2005. MMWR Morb Mortal Weekly Rep. 2006; 55:1221-1224. [published correction appears in MMWR Morb Mortal Weekly Rep. 2006;55:1303]. [EL 3].

21. Leslie WD, O’Donnell S, Jean S, et al. Osteoporosis Surveillance Expert Working Group. Trends in hip fracture rates in Canada. JAMA. 2009; 302:883-889. [EL 3]. [PubMed: 19706862]

22. Huusko TM, Karppi P, Avikainen V, Kautiainen H, Sulkava R. The changing picture of hip fractures: dramatic change in age distribution and no change in age-adjusted incidence within 10 years in Central Finland. Bone. 1999; 24:257-259. [EL 3]. [PubMed: 10071919]

23. Newman ED, Ayoub WT, Starkey RH, Diehl JM, Wood GC. Osteoporosis disease management in a rural health care population: hip fracture reduction and reduced costs in postmenopausal women after 5 years. Osteoporos Int. 2003; 14:146-151. [EL 3]. [PubMed: 12730773]

24. Dell R, Greene D, Schelkun SR, Williams K. Osteoporosis disease management: the role of the orthopaedic surgeon. J Bone Joint Surg Am. 2008; 90(suppl 4):188-194. [EL 2]. [PubMed: 18984730]

25. Chevalley T, Guilley E, Herrmann FR, Hoffmeyer P, Rapin CH, Rizzoli R. Incidence of hip fracture over a 10-year period (1991-2000): reversal of a secular trend. Bone. 2007; 40:12841289. [EL 3]. [PubMed: 17292683]

26. Kilgore ML, Morrisey MA, Becker DJ, et al. Health care expenditures associated with skeletal fractures among Medicare beneficiaries, 1999-2005. J Bone Miner Res. 2009; 24:2050-2055. [EL 2]. [PubMed: 19453260]

27. Cadarette SM, Katz JN, Brookhart MA, et al. Trends in drug prescribing for osteoporosis after hip fracture, 1995-2004. J Rheumatol. 2008; 35:319-326. [EL 3]. [PubMed: 18061977]

28. Lin YC, Lyle RM, Weaver CM, et al. Peak spine and femoral neck bone mass in young women. Bone. 2003; 32:546-553. [EL 2]. [PubMed: 12753871]

29. Matkovic V, Jelic T, Wardlaw GM, et al. Timing of peak bone mass in Caucasian females and its implication for the prevention of osteoporosis: inference from a cross-sectional model. J Clin Invest. 1994; 93:799-808. [EL 3]. [PubMed: 8113412]

30. Brown LB, Streeten EA, Shapiro JR, et al. Genetic and environmental influences on bone mineral density in pre- and post-menopausal women. Osteoporos Int. 2005; 16:1849-1856. [EL 2]. [PubMed: 15997421]

31. Recker RR, Deng HW. Role of genetics in osteoporosis. Endocrine. 2002; 17:55-66. [EL 4]. [PubMed: 12014706]

32. Williams F. Genetic regulation of bone mass and susceptibility to osteoporosis. J Musculoskel Neuron Interact. 2006; 6:27-35. [EL 3].

33. Richards JB, Kavvoura FK, Rivadeneira F, et al. Genetic Factors for Osteoporosis Consortium. Collaborative meta-analysis: associations of 150 candidate genes with osteoporosis and osteoporotic fracture. Ann Intern Med. 2009; 151:528-537. [EL 2]. [PubMed: 19841454] 
34. Vega D, Maalouf NM, Sakhaee K. The role of receptor activator of nuclear factor-kappaB (RANK)/RANK ligand/osteoprotegerin: clinical implications. J Clin Endocrinol Metab. 2007; 92:4514-4521. [EL 4]. [PubMed: 17895323]

35. Mackey DC, Lui LY, Cawthon PM, et al. Study of Osteoporotic Fractures [SOF] and Osteoporotic Fractures in Men Study [MrOS] Research Groups. High-trauma fractures and low bone mineral density in older women and men. JAMA. 2007; 298:2381-2388. [EL 2]. [PubMed: 18042915]

36. Orwig DL, Chan J, Magaziner J. Hip fracture and its consequences: differences between men and women. Orthop Clin North Am. 2006; 37:611-622. [EL 4]. [PubMed: 17141019]

37. Green AD, Colón-Emeric CS, Bastian L, Drake MT, Lyles KW. Does this woman have osteoporosis? JAMA. 2004; 292:2890-2900. [EL 3]. [PubMed: 15598921]

38. Kanis, JA. World Health Organisation Scientific Group. Assessment of Osteoporosis at the Primary Health Care Level: WHO Scientific Technical Report. Sheffield, UK: WHO Collaborating Centre for Metabolic Bone Diseases, University of Sheffield; 2008. [EL 4]

39. Watts NB, Ettinger B, LeBoff MS. FRAX facts. J Bone Miner Res. 2009; 24:975-979. [EL 4]. [PubMed: 19364271]

40. Watts NB, Lewiecki EM, Miller PD, Baim S. National Osteoporosis Foundation 2008 Clinician's Guide to Prevention and Treatment of Osteoporosis and the World Health Organization Fracture Risk Assessment Tool (FRAX): what they mean to the bone densitometrist and bone technologist. J Clin Densitom. 2008; 11:473-477. [EL 4]. [PubMed: 18562228]

41. Rud B, Hilden J, Hyldstrup L, Hróbjartsson A. Performance of the Osteoporosis Self-Assessment Tool in ruling out low bone mineral density in postmenopausal women: a systematic review. Osteoporos Int. 2007; 18:1177-1187. [published correction appears in Osteoporos Int. 2007;18:1307]. [EL 4]. [PubMed: 17361324]

42. Kanis JA, Oden A, Johnell O, et al. The use of clinical risk factors enhances the performance of BMD in the prediction of hip and osteoporotic fractures in men and women. Osteoporos Int. 2007; 18:1033-1046. [EL 2]. [PubMed: 17323110]

43. Kanis JA, Johnell O, De Laet C, et al. A meta-analysis of previous fracture and subsequent fracture risk. Bone. 2004; 35:375-382. [EL 2]. [PubMed: 15268886]

44. Klotzbuecher CM, Ross PD, Landsman PB, Abbott TA III, Berger M. Patients with prior fractures have an increased risk of future fractures: a summary of the literature and statistical synthesis. J Bone Miner Res. 2000; 15:721-739. [EL 4]. [PubMed: 10780864]

45. Cummings SR, Cawthon PM, Ensrud KE, Cauley JA, Fink HA, Orwoll ES. Osteoporotic Fractures in Men [MrOS] Research Groups; Study of Osteoporotic Fractures Research Groups. BMD and risk of hip and nonvertebral fractures in older men: a prospective study and comparison with older women. J Bone Miner Res. 2006; 21:1550-1556. [EL 2]. [PubMed: 16995809]

46. Johnell O, Kanis JA, Oden A, et al. Predictive value of BMD for hip and other fractures. J Bone Miner Res. 2005; 20:1185-1194. [published correction appears in J Bone Miner Res. 2007;22:774]. [EL 2]. [PubMed: 15940371]

47. Marshall D, Johnell O, Wedel H. Meta-analysis of how well measures of bone mineral density predict occurrence of osteoporotic fractures. BMJ. 1996; 312:1254-1259. [EL 2]. [PubMed: 8634613]

48. Kanis JA, Johnell O, Oden A, Dawson A, De Laet C, Jonsson B. Ten year probabilities of osteoporotic fractures according to BMD and diagnostic thresholds. Osteoporos Int. 2001; 12:989995. [EL 1]. [PubMed: 11846333]

49. Sambrook PN, Cameron ID, Chen JS, et al. Influence of fall related factors and bone strength on fracture risk in the frail elderly. Osteoporos Int. 2007; 18:603-610. [EL 2]. [PubMed: 17216131]

50. Misra M, Klibanski A. Anorexia nervosa and osteoporosis. Rev Endocr Metab Disord. 2006; 7:9199. [EL 4]. [PubMed: 16972186]

51. Rizzoli R, Ammann P, Chevalley T, Bonjour JP. Protein intake and bone disorders in the elderly. Joint Bone Spine. 2001; 68:383-392. [EL 4]. [PubMed: 11707004]

52. Schürch MA, Rizzoli R, Slosman D, Vadas L, Vergnaud P, Bonjour JP. Protein supplements increase serum insulin-like growth factor-I levels and attenuate proximal femur bone loss in patients with recent hip fracture: a randomized, double-blind, placebo-controlled trial. Ann Intern Med. 1998; 128:801-809. [EL 1]. [PubMed: 9599191] 
53. Ross AC, Manson JE, Abrams SA, et al. The 2011 report on dietary reference intakes for calcium and vitamin D from the Institute of Medicine: what clinicians need to know. J Clin Endocrinol Metab. [published online ahead of print November 29, 2010].

54. Chan GM, Hoffman K, McMurry M. Effects of dairy products on bone and body composition in pubertal girls. J Pediatr. 1995; 126:551-556. [EL 1]. [PubMed: 7699532]

55. Gibbons MJ, Gilchrist NL, Frampton C, et al. The effects of a high calcium dairy food on bone health in pre-pubertal children in New Zealand. Asia Pac J Clin Nutr. 2004; 13:341-347. [EL 1]. [PubMed: 15563438]

56. Ho SC, Guldan GS, Woo J, et al. A prospective study of the effects of 1-year calcium-fortified soy milk supplementation on dietary calcium intake and bone health in Chinese adolescent girls aged 14 to 16. Osteoporos Int. 2005; 16:1907-1916. [EL 2]. [PubMed: 16133646]

57. Merrilees MJ, Smart EJ, Gilchrist NL, et al. Effects of dairy food supplements on bone mineral density in teenage girls. Eur J Nutr. 2000; 39:256-262. [EL 2]. [PubMed: 11395985]

58. Winzenberg T, Shaw K, Fryer J, Jones G. Effects of calcium supplementation on bone density in healthy children: meta-analysis of randomised controlled trials. BMJ. 2006; 333:775. [EL 1]. [PubMed: 16980314]

59. Alaimo, K.; McDowell, MA.; Briefel, RR., et al. Advance data from vital and health statistics, No. 258. Hyattsville, MD: National Center for Health Statistics; 1994. Dietary intake of vitamins, minerals, and fiber of persons ages 2 months and over in the United States: Third National Health and Nutrition Examination Survey, phase 1, 1988-91; p. 1-28.[EL 3]

60. Porthouse J, Cockayne S, King C, et al. Randomised controlled trial of calcium and supplementation with cholecalciferol (vitamin D3) for prevention of fractures in primary care. BMJ. 2005; 330:1003. [EL 1]. [PubMed: 15860827]

61. Shea B, Wells G, Cranney A, et al. Osteoporosis Methodology Group and the Osteoporosis Research Advisory Group. Meta-analyses of therapies for postmenopausal osteoporosis, VII: meta-analysis of calcium supplementation for the prevention of postmenopausal osteoporosis. Endocr Rev. 2002; 23:552-559. [EL 1]. [PubMed: 12202470]

62. Jackson RD, LaCroix AZ, Gass M, et al. Women's Health Initiative Investigators. Calcium plus vitamin D supplementation and the risk of fractures. N Engl J Med. 2006; 354:669-683. [EL 1]. [PubMed: 16481635]

63. Grant AM, Avenell A, Campbell MK, et al. RECORD Trial Group. Oral vitamin D3 and calcium for secondary prevention of low-trauma fractures in elderly people (Randomised Evaluation of Calcium OR vitamin D, RECORD): a randomised placebo-controlled trial. Lancet. 2005; 365:1621-1628. [EL 1]. [PubMed: 15885294]

64. Holick MF, Siris ES, Binkley N, et al. Prevalence of vitamin D inadequacy among postmenopausal North American women receiving osteoporosis therapy. J Clin Endocrinol Metab. 2005; 90:32153224. [EL 2]. [PubMed: 15797954]

65. Dawson-Hughes B, Heaney RP, Holick MF, Lips P, Meunier PJ, Vieth R. Estimates of optimal vitamin D status. Osteoporos Int. 2005; 16:713-716. [EL 4]. [PubMed: 15776217]

66. Binkley N, Novotny R, Krueger D, et al. Low vitamin D status despite abundant sun exposure. J Clin Endocrinol Metab. 2007; 92:2130-2135. [EL 3]. [PubMed: 17426097]

67. Bischoff-Ferrari HA, Willett WC, Wong JB, Giovannucci E, Dietrich T, Dawson-Hughes B. Fracture prevention with vitamin D supplementation: a meta-analysis of randomized controlled trials. JAMA. 2005; 293:2257-2264. [EL 2]. [PubMed: 15886381]

68. Bischoff-Ferrari HA, Dawson-Hughes B, Willett WC, et al. Effect of vitamin D on falls: a metaanalysis. JAMA. 2004; 291:1999-2006. [EL 2]. [PubMed: 15113819]

69. Bischoff-Ferrari HA, Conzelmann M, Stähelin HB, et al. Is fall prevention by vitamin D mediated by a change in postural or dynamic balance? Osteoporos Int. 2006; 17:656-663. [EL 2]. [PubMed: 16508700]

70. Pfeifer M, Begerow B, Minne HW, Abrams C, Nachtigall D, Hansen C. Effects of a short-term vitamin $\mathrm{D}$ and calcium supplementation on body sway and secondary hyperparathyroidism in elderly women. J Bone Miner Res. 2000; 15:1113-1118. [published corrections appear in J Bone Miner Res. 2001;16:1735, 1935]. [EL 2]. [PubMed: 10841179] 
71. Autier P, Gandini S. Vitamin D supplementation and total mortality: a meta-analysis of randomized controlled trials. Arch Intern Med. 2007; 167:1730-1737. [EL 2]. [PubMed: 17846391]

72. Holick MF, Biancuzzo RM, Chen TC, et al. Vitamin D2 is as effective as vitamin D3 in maintaining circulating concentrations of 25-hydroxyvitamin D. J Clin Endocrinol Metab. 2008; 93:677-681. [EL 1]. [PubMed: 18089691]

73. Armas LA, Hollis BW, Heaney RP. Vitamin D2 is much less effective than vitamin D3 in humans. J Clin Endocrinol Metab. 2004; 89:5387-5391. [EL 2]. [PubMed: 15531486]

74. Spencer H, Fuller H, Norris C, Williams D. Effect of magnesium on the intestinal absorption of calcium in man. J Am Coll Nutr. 1994; 13:485-492. [EL 1]. [PubMed: 7836628]

75. Jackson HA, Sheehan AH. Effect of vitamin A on fracture risk. Ann Pharmacother. 2005; 39:2086-2090. [EL 4]. [PubMed: 16249271]

76. Braam LA, Knapen MH, Geusens P, et al. Vitamin K1 supplementation retards bone loss in postmenopausal women between 50 and 60 years of age. Calcif Tissue Int. 2003; 73:21-26. [EL 1]. [PubMed: 14506950]

77. Alexandersen P, Toussaint A, Christiansen C, et al. Ipraflavone Multicenter European Fracture Study. Ipriflavone in the treatment of postmenopausal osteoporosis: a randomized controlled trial. JAMA. 2001; 285:1482-1488. [EL 1]. [PubMed: 11255425]

78. Atkinson C, Compston JE, Day NE, Dowsett M, Bingham SA. The effects of phytoestrogen isoflavones on bone density in women: a double-blind, randomized, placebo-controlled trial. Am J Clin Nutr. 2004; 79:326-333. [EL 1]. [PubMed: 14749241]

79. Gallagher JC, Satpathy R, Rafferty K, Haynatzka V. The effect of soy protein isolate on bone metabolism. Menopause. 2004; 11:290-298. [EL 2]. [PubMed: 15167308]

80. Kanis JA, Johansson H, Johnell O, et al. Alcohol intake as a risk factor for fracture. Osteoporos Int. 2005; 16:737-742. [EL 2]. [PubMed: 15455194]

81. Hallström H, Wolk A, Glynn A, Michaëlsson K. Coffee, tea and caffeine consumption in relation to osteoporotic fracture risk in a cohort of Swedish women. Osteoporos Int. 2006; 17:1055-1064. [EL 3]. [PubMed: 16758142]

82. Kiel DP, Felson DT, Hannan MT, Anderson JJ, Wilson PW. Caffeine and the risk of hip fracture: the Framingham Study. Am J Epidemiol. 1990; 132:675-684. [EL 3]. [PubMed: 2403108]

83. Kanis JA, Johnell O, Oden A, et al. Smoking and fracture risk: a meta-analysis. Osteoporos Int. 2005; 16:155-162. [EL 2]. [PubMed: 15175845]

84. Snow-Harter C, Bouxsein M, Lewis B, Charette S, Weinstein P, Marcus R. Muscle strength as a predictor of bone mineral density in young women. J Bone Miner Res. 1990; 5:589-595. [EL 2]. [PubMed: 2382585]

85. Snow-Harter C, Bouxsein ML, Lewis BT, Carter DR, Marcus R. Effects of resistance and endurance exercise on bone mineral status of young women: a randomized exercise intervention trial. J Bone Miner Res. 1992; 7:761-769. [EL 1]. [PubMed: 1642145]

86. Kelley GA, Kelley KS, Tran ZV. Exercise and lumbar spine bone mineral density in postmenopausal women: a meta-analysis of individual patient data. J Gerontol A Biol Sci Med Sci. 2002; 57:M599-M604. [EL 2]. [PubMed: 12196498]

87. Gardner MM, Phty M, Robertson MC, McGee R, Campbell AJ. Application of a falls prevention program for older people to primary health care practice. Prev Med. 2002; 34:546-553. [EL 2]. [PubMed: 11969356]

88. Robertson MC, Campbell AJ, Gardner MM, Devlin N. Preventing injuries in older people by preventing falls: a meta-analysis of individual-level data. J Am Geriatr Soc. 2002; 50:905-911. [EL 2]. [PubMed: 12028179]

89. Parker MJ, Gillespie WJ, Gillespie LD. Effectiveness of hip protectors for preventing hip fractures in elderly people: systematic review. BMJ. 2006; 332:571-574. [EL 2]. [PubMed: 16513687]

90. Sawka AM, Boulos P, Beattie K, et al. Do hip protectors decrease the risk of hip fracture in institutional and community-dwelling elderly? A systematic review and meta-analysis of randomized controlled trials. Osteoporos Int. 2005; 16:1461-1474. [EL 1]. [PubMed: 15990949]

91. Singh S, Sun H, Anis AH. Cost-effectiveness of hip protectors in the prevention of osteoporosis related hip fractures in elderly nursing home residents. J Rheumatol. 2004; 31:1607-1613. [EL 3]. [PubMed: 15290742] 
92. van Schoor NM, Asma G, Smit JH, Bouter LM, Lips P. The Amsterdam Hip Protector Study: compliance and determinants of compliance. Osteoporos Int. 2003; 14:353-359. [EL 2]. [PubMed: 12730735]

93. Warnke A, Meyer G, Bender R, Mühlhauser I. Predictors of adherence to the use of hip protectors in nursing home residents. J Am Geriatr Soc. 2004; 52:340-345. [EL 2]. [PubMed: 14962146]

94. Kiel DP, Magaziner J, Zimmerman S, et al. Efficacy of a hip protector to prevent hip fracture in nursing home residents: the HIP PRO randomized controlled trial. JAMA. 2007; 298:413-422. [EL 1]. [PubMed: 17652295]

95. Li WC, Chen YC, Yang RS, Tsauo JY. Effects of exercise programmes on quality of life in osteoporotic and osteopenic postmenopausal women: a systematic review and meta-analysis. Clin Rehabil. 2009; 23:888-896. [EL 1]. [PubMed: 19717503]

96. Lewiecki EM, Laster AJ. Clinical review: clinical applications of vertebral fracture assessment by dual-energy x-ray absorptiometry. J Clin Endocrinol Metab. 2006; 91:4215-4222. [EL 4]. [PubMed: 16940447]

97. Schneider DL, von Mühlen D, Barrett-Connor E, Sartoris DJ. Kyphosis does not equal vertebral fractures: the Rancho Bernardo study. J Rheumatol. 2004; 31:747-752. [EL 2]. [PubMed: 15088302]

98. Siminoski K, Jiang G, Adachi JD, et al. Accuracy of height loss during prospective monitoring for detection of incident vertebral fractures. Osteoporos Int. 2005; 16:403-410. [EL 2]. [PubMed: 15309381]

99. Siminoski K, Warshawski RS, Jen H, Lee K. The accuracy of historical height loss for the detection of vertebral fractures in postmenopausal women. Osteoporos Int. 2006; 17:290-296. [EL 2]. [PubMed: 16143833]

100. Barr RJ, Stewart A, Torgerson DJ, Reid DM. Population screening for osteoporosis risk: a randomised control trial of medication use and fracture risk. Osteoporos Int. 2009; 21:561-568. [EL 1]. [PubMed: 19565176]

101. Tannenbaum C, Clark J, Schwartzman K, et al. Yield of laboratory testing to identify secondary contributors to osteoporosis in otherwise healthy women. J Clin Endocrinol Metab. 2002; 87:4431-4437. [EL 2]. [PubMed: 12364413]

102. Barzel US. Recommended testing in patients with low bone density [with author reply]. J Clin Endocrinol Metab. 2003; 88:1404-1405. [EL 4]. [PubMed: 12629143]

103. Chesnut CH III, Bell NH, Clark GS, et al. Hormone replacement therapy in postmenopausal women: urinary N-telopeptide of type I collagen monitors therapeutic effect and predicts response of bone mineral density. Am J Med. 1997; 102:29-37. [EL 1]. [PubMed: 9209198]

104. Garnero P, Hausherr E, Chapuy MC, et al. Markers of bone resorption predict hip fracture in elderly women: the EPIDOS Prospective Study. J Bone Miner Res. 1996; 11:1531-1538. [EL 2]. [PubMed: 8889854]

105. Greenspan SL, Rosen HN, Parker RA. Early changes in serum N-telopeptide and C-telopeptide cross-linked collagen type 1 predict long-term response to alendronate therapy in elderly women. J Clin Endocrinol Metab. 2000; 85:3537-3540. [EL 1]. [PubMed: 11061497]

106. National Osteoporosis Foundation. Clinician's Guide to Prevention and Treatment of Osteoporosis. Washington, DC: National Osteoporosis Foundation; 2008. http://www.nof.org/ sites/default/files/pdfs/NOF_Clinicians_Guide2008.pdf. [EL 4] [Accessed for verification November 7, 2010]

107. Jamal SA, Bauer DC, Ensrud KE, et al. Alendronate treatment in women with normal to severely impaired renal function: an analysis of the Fracture Intervention Trial. J Bone Miner Res. 2007; 22:503-508. [EL 2]. [PubMed: 17243862]

108. Miller PD, Roux C, Boonen S, Barton IP, Dunlap LE, Burgio DE. Safety and efficacy of risedronate in patients with age-related reduced renal function as estimated by the Cockcroft and Gault method: a pooled analysis of nine clinical trials. J Bone Miner Res. 2005; 20:2105-2115. [EL 1]. [PubMed: 16294264]

109. Kidney Disease: Improving Global Outcomes (KDIGO) CKD-MBD Work Group. KDIGO clinical practice guideline for the diagnosis, evaluation, prevention, and treatment of chronic 
kidney disease-mineral and bone disorders (CKD-MBD). Kidney Int Suppl. 2009 Aug; 76(suppl 113):S1-S130.

110. Adami S, Bhalla AK, Dorizzi R, et al. The acute-phase response after bisphosphonate administration. Calcif Tissue Int. 1987; 41:326-331. [EL 3]. [PubMed: 3124942]

111. Jones SG, Dolan G, Lengyel K, Myers B. Severe increase in creatinine with hypocalcaemia in thalidomide-treated myeloma patients receiving zoledronic acid infusions. Br J Haematol. 2002; 119:576-577. [EL 3]. [PubMed: 12406106]

112. Chang JT, Green L, Beitz J. Renal failure with the use of zoledronic acid [letter]. N Engl J Med. 2003; 349:1676-1678. [EL 3]. [PubMed: 14573746]

113. Tarassoff P, Hei YJ, Maladorno D. Renal failure with the use of zoledronic acid [reply to letter]. N Engl J Med. 2003; 349:1678-1679. [EL 3].

114. FDA U.S. Food and Drug Administration. Zoledronic acid for osteoporosis (marketed as Reclast): renal impairment and acute renal failure. Drug Safety Newsletter. 2009; 2:13-15. http:// www.fda.gov/Drugs/DrugSafety/DrugSafetyNewsletter/default.htm. [EL 3].

115. Wysowski DK, Chang JT. Alendronate and risedronate: reports of severe bone, joint, and muscle pain. Arch Intern Med. 2005; 165:346-347. [EL 3]. [PubMed: 15710802]

116. Woo SB, Hellstein JW, Kalmar JR. Narrative [corrected] review: bisphosphonates and osteonecrosis of the jaws. Ann Intern Med. 2006; 144:753-761. [published correction appears in Ann Intern Med. 2006;145:235]. [EL 4]. [PubMed: 16702591]

117. Bilezikian J. Osteonecrosis of the jaw—do bisphosphonates pose a risk? N Engl J Med. 2006; 355:2278-2282. [EL 4]. [PubMed: 17135582]

118. Khosla S, Burr D, Cauley J, et al. American Society for Bone and Mineral Research. Bisphosphonate-associated osteonecrosis of the jaw: report of a task force of the American Society for Bone and Mineral Research. J Bone Miner Res. 2007; 22:1479-1491. [EL 4]. [PubMed: 17663640]

119. Bauer DC, Black D, Ensrud K, et al. Upper gastrointestinal tract safety profile of alendronate: the Fracture Intervention Trial. Arch Intern Med. 2000; 160:517-525. [EL 1]. [PubMed: 10695692]

120. Lenart BA, Neviaser AS, Lyman S, et al. Association of low-energy femoral fractures with prolonged bisphosphonate use: a case control study. Osteoporos Int. 2009; 20:1353-1362. [EL 2]. [PubMed: 19066707]

121. Watts N, Freedholm D, Daifotis A. The clinical tolerability profile of alendronate. Int J Clin Pract Suppl. 1999; 101:51-61. [EL 4]. [PubMed: 12669741]

122. de Groen PC, Lubbe DF, Hirsch LJ, et al. Esophagitis associated with the use of alendronate. N Engl J Med. 1996; 335:1016-1021. [EL 3]. [PubMed: 8793925]

123. Shane E, Burr D, Ebeling PR, et al. Atypical subtrochanteric and diaphyseal femoral fractures: report of a task force of the American Society for Bone and Mineral Research. J Bone Miner Res. 2010; 25:2267-2294. [PubMed: 20842676]

124. Cardwell CR, Abnet CC, Cantwell MM, Murray LJ. Exposure to oral bisphosphonates and risk of esophageal cancer. JAMA. 2010; 304:657-663. [EL 2]. [PubMed: 20699457]

125. Green J, Czanner G, Reeves G, Watson J, Wise L, Beral V. Oral bisphosphonates and risk of cancer of oesophagus, stomach, and colorectum: case-control analysis within a UK primary care cohort. BMJ. 2010; 341:c4444. [EL 2]. [PubMed: 20813820]

126. Black DM, Delmas PD, Eastell R, et al. HORIZON Pivotal Fracture Trial. Once-yearly zoledronic acid for treatment of postmenopausal osteoporosis. N Engl J Med. 2007; 356:1809-1822. [EL 1]. [PubMed: 17476007]

127. Fosamax [package insert]. Whitehouse Station, NJ: Merck \& Co., Inc.; 2010.

128. Black DM, Cummings SR, Karpf DB, et al. Fracture Intervention Trial Research Group. Randomised trial of effect of alendronate on risk of fracture in women with existing vertebral fractures. Lancet. 1996; 348:1535-1541. [EL 1]. [PubMed: 8950879]

129. Cummings SR, Black DM, Thompson DE, et al. Effect of alendronate on risk of fracture in women with low bone density but without vertebral fractures: results from the Fracture Intervention Trial. JAMA. 1998; 280:2077-2082. [EL 1]. [PubMed: 9875874]

130. Black DM, Thompson DE, Bauer DC, et al. Fracture Intervention Trial [FIT] Research Group. Fracture risk reduction with alendronate in women with osteoporosis: the Fracture Intervention 
Trial. J Clin Endocrinol Metab. 2000; 85:4118-4124. [published correction appears in J Clin Endocrinol Metab. 2001;86:938]. [EL 2]. [PubMed: 11095442]

131. Pols HA, Felsenberg D, Hanley DA, et al. Fosamax International Trial Study Group. Multinational, placebo-controlled, randomized trial of the effects of alendronate on bone density and fracture risk in postmenopausal women with low bone mass: results of the FOSIT study. Osteoporos Int. 1999; 9:461-468. [EL 1]. [PubMed: 10550467]

132. Liberman UA, Weiss SR, Bröll J, et al. Alendronate Phase III Osteoporosis Treatment Study Group. Effect of oral alendronate on bone mineral density and the incidence of fractures in postmenopausal osteoporosis. N Engl J Med. 1995; 333:1437-1443. [EL 1]. [PubMed: 7477143]

133. Bone HG, Hosking D, Devogelaer JP, et al. Alendronate Phase III Osteoporosis Treatment Study Group. Ten years' experience with alendronate for osteoporosis in postmenopausal women. N Engl J Med. 2004; 350:1189-1199. [EL 4]. [PubMed: 15028823]

134. Black DM, Schwartz AV, Ensrud KE, et al. Effects of continuing or stopping alendronate after 5 years of treatment: the Fracture Intervention Trial Long-term Extension (FLEX); a randomized trial. JAMA. 2006; 296:2927-2938. [EL 1]. [PubMed: 17190893]

135. Castell DO. "Pill esophagitis"- the case of alendronate. N Engl J Med. 1996; 335:1058-1059. [EL 3]. [PubMed: 8793934]

136. Famularo G, De Simone C. Fatal esophageal perforation with alendronate. Am J Gastroenterol. 2001; 96:3212-3213. [EL 3]. [PubMed: 11721784]

137. Donahue JG, Chan KA, Andrade SE, et al. Gastric and duodenal safety of daily alendronate. Arch Intern Med. 2002; 162:936-942. [EL 2]. [PubMed: 11966346]

138. Greenspan S, Field-Munves E, Tonino R, et al. Tolerability of once-weekly alendronate in patients with osteoporosis: a randomized, double-blind, placebo-controlled study. Mayo Clin Proc. 2002; 77:1044-1052. [EL 1]. [PubMed: 12374248]

139. Watts NB, Diab DL. Long-term use of bisphosphonates in osteoporosis. J Clin Endocrinol Metab. 2010; 95:1555-1565. [EL 4]. [PubMed: 20173017]

140. Actonel [package insert]. Cincinnati, OH: Procter \& Gamble Pharmaceuticals, Inc.; 2010.

141. Harris ST, Watts NB, Genant HK, et al. Vertebral Efficacy With Risedronate Therapy [VERT] Study Group. Effects of risedronate treatment on vertebral and nonvertebral fractures in women with postmenopausal osteoporosis: a randomized controlled trial. JAMA. 1999; 282:1344-1352. [EL 1]. [PubMed: 10527181]

142. Reginster J, Minne HW, Sorensen OH, et al. Vertebral Efficacy With Risedronate Therapy [VERT] Study Group. Randomized trial of the effects of risedronate on vertebral fractures in women with established postmenopausal osteoporosis. Osteoporos Int. 2000; 11:83-91. [EL 1]. [PubMed: 10663363]

143. McClung MR, Geusens P, Miller PD, et al. Hip Intervention Program Study Group. Effect of risedronate on the risk of hip fracture in elderly women. N Engl J Med. 2001; 344:333-340. [EL 1]. [PubMed: 11172164]

144. Sorensen OH, Crawford GM, Mulder H, et al. Long-term efficacy of risedronate: a 5-year placebo-controlled clinical experience. Bone. 2003; 32:120-126. [EL 1]. [PubMed: 12633783]

145. Mellström DD, Sörensen OH, Goemaere S, Roux C, Johnson TD, Chines AA. Seven years of treatment with risedronate in women with postmenopausal osteoporosis. Calcif Tissue Int. 2004; 75:462-468. [EL 2]. [PubMed: 15455188]

146. Watts NB, Chines A, Olszynski WP, et al. Fracture risk remains reduced one year after discontinuation of risedronate. Osteoporos Int. 2008; 19:365-372. [EL 1]. [PubMed: 17938986]

147. Boniva [package insert]. Nutley, NJ: Roche Therapeutics Inc.; 2010.

148. Chesnut CH III, Skag A, Christiansen C, et al. Oral Ibandronate Osteoporosis Vertebral Fracture Trial in North America and Europe [BONE]. Effects of oral ibandronate administered daily or intermittently on fracture risk in postmenopausal osteoporosis. J Bone Miner Res. 2004; 19:1241-1249. [EL 1]. [PubMed: 15231010]

149. McClung MR, Wasnich RD, Recker R, et al. Oral Ibandronate Study Group. Oral daily ibandronate prevents bone loss in early postmenopausal women without osteoporosis. J Bone Miner Res. 2004; 19:11-18. [EL 1]. [PubMed: 14753731]

150. Reclast [package insert]. East Hanover, NJ: Novartis Pharmaceuticals Corporation; 2010. 
151. McClung M, Recker R, Miller P, et al. Intravenous zoledronic acid $5 \mathrm{mg}$ in the treatment of postmenopausal women with low bone density previously treated with alendronate. Bone. 2007; 41:122-128. [EL 1]. [PubMed: 17468062]

152. Reid DM, Devogelaer JP, Saag K, et al. HORIZON Investigators. Zoledronic acid and risedronate in the prevention and treatment of glucocorticoid-induced osteoporosis (HORIZON): a multicentre, double-blind, double-dummy, randomised controlled trial. Lancet. 2009; 373:12531263. [EL 1]. [PubMed: 19362675]

153. Delmas PD, Bjarnason NH, Mitlak BH, et al. Effects of raloxifene on bone mineral density, serum cholesterol concentrations, and uterine endometrium in postmenopausal women. N Engl J Med. 1997; 337:1641-1647. [EL 1]. [PubMed: 9385122]

154. Evista [package insert]. Indianapolis, IN: Eli Lilly and Company; 2008.

155. Ettinger B, Black DM, Mitlak BH, et al. Multiple Outcomes of Raloxifene Evaluation [MORE] Investigators. Reduction of vertebral fracture risk in postmenopausal women with osteoporosis treated with raloxifene: results from a 3-year randomized clinical trial. JAMA. 1999; 282:637645. [EL 1]. [PubMed: 10517716]

156. Delmas PD, Ensrud KE, Adachi JD, et al. Multiple Outcomes of Raloxifene Evaluation Investigators. Efficacy of raloxifene on vertebral fracture risk reduction in postmenopausal women with osteoporosis: four-year results from a randomized clinical trial. J Clin Endocrinol Metab. 2002; 87:3609-3617. [EL 1]. [PubMed: 12161484]

157. Barrett-Connor E, Mosca L, Collins P, et al. Raloxifene Use for the Heart [RUTH] Trial Investigators. Effects of raloxifene on cardiovascular events and breast cancer in postmenopausal women. N Engl J Med. 2006; 355:125-137. [EL 1]. [PubMed: 16837676]

158. Vogel VG, Costantino JP, Wickerham DL, et al. National Surgical Adjuvant Breast and Bowel Project [NSABP]. Effects of tamoxifen vs raloxifene on the risk of developing invasive breast cancer and other disease outcomes: the NSABP Study of Tamoxifen and Raloxifene (STAR) P-2 trial. JAMA. 2006; 295:2727-2741. [published corrections appear in JAMA 2006;296:2926 and JAMA. 2007;298:973]. [EL 1]. [PubMed: 16754727]

159. Siris ES, Harris ST, Eastell R, et al. Continuing Outcomes Relevant to Evista [CORE] Investigators. Skeletal effects of raloxifene after 8 years: results from the Continuing Outcomes Relevant to Evista (CORE) study. J Bone Miner Res. 2005; 20:1514-1524. [EL 1]. [PubMed: 16059623]

160. Forteo [package insert]. Indianapolis, IN: Eli Lilly and Company; 2010.

161. Neer RM, Arnaud CD, Zanchetta JR, et al. Effect of parathyroid hormone (1-34) on fractures and bone mineral density in postmenopausal women with osteoporosis. N Engl J Med. 2001; 344:1434-1441. [EL 1]. [PubMed: 11346808]

162. Watts NB, Miller PD, Kohlmeier LA, et al. Vertebral fracture risk is reduced in women who lose femoral neck BMD with teriparatide treatment. J Bone Miner Res. 2009; 24:1125-1131. [EL 2]. [PubMed: 19113918]

163. Vahle JL, Sato M, Long GG, et al. Skeletal changes in rats given daily subcutaneous injections of recombinant human parathyroid hormone (1-34) for 2 years and relevance to human safety. Toxicol Pathol. 2002; 30:312-321. [EL 1]. [PubMed: 12051548]

164. Vahle JL, Long GG, Sandusky G, Westmore M, Ma YL, Sato M. Bone neoplasms in F344 rats given teriparatide $[\mathrm{rhPTH}(1-34)]$ are dependent on duration of treatment and dose. Toxicol Pathol. 2004; 32:426-438. [EL 1]. [PubMed: 15204966]

165. Harper KD, Krege JH, Marcus R, Mitlak BH. Osteosarcoma and teriparatide? J Bone Miner Res. 2007; 22:334. [EL 4]. [PubMed: 17129179]

166. Subbiah V, Madsen VS, Raymond AK, Benjamin RS, Ludwig JA. Of mice and men: divergent risks of teriparatide-induced osteosarcoma. Osteoporos Int. 2010; 21:1041-1045. [EL 3]. [PubMed: 19597911]

167. Lindsay R, Scheele WH, Neer R, et al. Sustained vertebral fracture risk reduction after withdrawal of teriparatide in postmenopausal women with osteoporosis. Arch Intern Med. 2004; 164:2024-2030. [EL 2]. [PubMed: 15477438] 
168. Black DM, Bilezikian JP, Ensrud KE, et al. PaTH Study Investigators. One year of alendronate after one year of parathyroid hormone (1-84) for osteoporosis. N Engl J Med. 2005; 353:555565. [EL 1]. [PubMed: 16093464]

169. Fortical [package insert]. Minneapolis, MN: Upsher-Smith Laboratories, Inc.; 2009.

170. Miacalcin [package insert]. East Hanover, NJ: Novartis Pharmaceuticals Corporation; 2009.

171. Chesnut CH III, Silverman S, Andriano K, et al. PROOF Study Group. A randomized trial of nasal spray salmon calcitonin in postmenopausal women with established osteoporosis: the Prevent Recurrence Of Osteoporotic Fractures study. Am J Med. 2000; 109:267-276. [EL 1]. [PubMed: 10996576]

172. Cummings SR, San Martin J, McClung MR, et al. FREEDOM Trial. Denosumab for prevention of fractures in postmenopausal women with osteoporosis. N Engl J Med. 2009; 361:756-765. [published correction appears in NEngl J Med. 2009;361:1914]. [EL 1]. [PubMed: 19671655]

173. Bone HG, Bolognese MA, Yuen CK, et al. Effects of denosumab on bone mineral density and bone turnover in postmenopausal women. J Clin Endocrinol Metab. 2008; 93:2149-2157. [EL 1]. [PubMed: 18381571]

174. Miller PD, Bolognese MA, Lewiecki EM, et al. AMG Bone Loss Study Group. Effect of denosumab on bone density and turnover in postmenopausal women with low bone mass after long-term continued, discontinued, and restarting of therapy: a randomized blinded phase 2 clinical trial. Bone. 2008; 43:222-229. [EL 1]. [PubMed: 18539106]

175. Premarin [package insert]. Philadelphia, PA: Ayerst Laboratories; 2010.

176. Cauley JA, Robbins J, Chen Z, et al. Women's Health Initiative Investigators. Effects of estrogen plus progestin on risk of fracture and bone mineral density: the Women's Health Initiative randomized trial. JAMA. 2003; 290:1729-1738. [EL 1]. [PubMed: 14519707]

177. Jackson RD, Wactawski-Wende J, LaCroix AZ, et al. Women's Health Initiative Investigators. Effects of conjugated equine estrogen on risk of fractures and BMD in postmenopausal women with hysterectomy: results from the Women's Health Initiative randomized trial. J Bone Miner Res. 2006; 21:817-828. [EL 1]. [PubMed: 16753012]

178. Writing Group for the PEPI. Effects of hormone therapy on bone mineral density: results from the Postmenopausal Estrogen/Progestin Interventions (PEPI) trial. JAMA. 1996; 276:1389-1396. [EL 1]. [PubMed: 8892713]

179. Genant HK, Lucas J, Weiss S, et al. Estratab/Osteoporosis Study Group. Low-dose esterified estrogen therapy: effects on bone, plasma estradiol concentrations, endometrium, and lipid levels. Arch Intern Med. 1997; 157:2609-2615. [EL 1]. [PubMed: 9531230]

180. Lindsay R, Gallagher JC, Kleerekoper M, Pickar JH. Effect of lower doses of conjugated equine estrogens with and without medroxyprogesterone acetate on bone in early postmenopausal women. JAMA. 2002; 287:2668-2676. [EL 1]. [PubMed: 12020302]

181. Rossouw JE, Anderson GL, Prentice RL, et al. Writing Group for the Women's Health Initiative Investigators. Risks and benefits of estrogen plus progestin in healthy postmenopausal women: principal results from the Women's Health Initiative randomized controlled trial. JAMA. 2002; 288:321-333. [EL 1]. [PubMed: 12117397]

182. Anderson GL, Limacher M, Assaf AR, et al. Women's Health Initiative Steering Committee. Effects of conjugated equine estrogen in postmenopausal women with hysterectomy: the Women's Health Initiative randomized controlled trial. JAMA. 2004; 291:1701-1712. [EL 1]. [PubMed: 15082697]

183. Gallagher JC, Rapuri PB, Haynatzki G, Detter JR. Effect of discontinuation of estrogen, calcitriol, and the combination of both on bone density and bone markers. J Clin Endocrinol Metab. 2002; 87:4914-4923. [EL 1]. [PubMed: 12414850]

184. Compston JE, Watts NB. Combination therapy for postmenopausal osteoporosis. Clin Endocrinol (Oxf). 2002; 56:565-569. [EL 4]. [PubMed: 12030903]

185. Black DM, Greenspan SL, Ensrud KE, et al. PaTH Study Investigators. The effects of parathyroid hormone and alendronate alone or in combination in postmenopausal osteoporosis. N Engl J Med. 2003; 349:1207-1215. [EL 1]. [PubMed: 14500804]

186. Watts NB, Harris ST, Genant HK, et al. Intermittent cyclical etidronate treatment of postmenopausal osteoporosis. N Engl J Med. 1990; 323:73-79. [EL 1]. [PubMed: 2113611] 
187. Aredia [package insert]. East Hanover, NJ: Novartis Pharmaceuticals Corporation; 2008.

188. Didronel [package insert]. Cincinnati, OH: Procter \& Gamble Pharmaceuticals, Inc.; 2010.

189. Peretz A, Body JJ, Dumon JC, et al. Cyclical pamidronate infusions in postmenopausal osteoporosis. Maturitas. 1996; 25:69-75. [EL 2]. [PubMed: 8887311]

190. Greenspan SL, Maitland LA, Myers ER, Krasnow MB, Kido TH. Femoral bone loss progresses with age: a longitudinal study in women over age 65. J Bone Miner Res. 1994; 9:1959-1965. [EL 2]. [PubMed: 7872062]

191. Ooms ME, Lips P, Roos JC, et al. Vitamin D status and sex hormone binding globulin: determinants of bone turnover and bone mineral density in elderly women. J Bone Miner Res. 1995; 10:1177-1184. [EL 2]. [PubMed: 8585420]

192. Lane NE. An update on glucocorticoid-induced osteoporosis. Rheum Dis Clin North Am. 2001; 27:235-253. [EL 4]. [PubMed: 11285998]

193. Lewiecki EM, Watts NB. Assessing response to osteoporosis therapy. Osteoporos Int. 2008; 19:1363-1368. [EL 4]. [PubMed: 18546030]

194. Lenchik L, Kiebzak GM, Blunt BA. International Society for Clinical Densitometry Position Development Panel and Scientific Advisory Committee. What is the role of serial bone mineral density measurements in patient management? J Clin Densitom. 2002; 5(suppl):S29-S38. [EL 4]. [PubMed: 12464709]

195. Baim S, Wilson CR, Lewiecki EM, Luckey MM, Downs RW Jr, Lentle BC. Precision assessment and radiation safety for dual-energy $\mathrm{x}$-ray absorptiometry: position paper of the International Society for Clinical Densitometry. J Clin Densitom. 2005; 8:371-378. [EL 4]. [PubMed: 16311420]

196. Bouxsein ML. Mechanisms of osteoporosis therapy: a bone strength perspective. Clin Cornerstone. 2003; 5(suppl 2):S13-S21. [EL 4]. [PubMed: 15035555]

197. Hochberg MC, Greenspan S, Wasnich RD, Miller P, Thompson DE, Ross PD. Changes in bone density and turnover explain the reductions in incidence of nonvertebral fractures that occur during treatment with antiresorptive agents. J Clin Endocrinol Metab. 2002; 87:1586-1592. [EL 1]. [PubMed: 11932287]

198. Tosteson AN, Grove MR, Hammond CS, et al. Early discontinuation of treatment for osteoporosis. Am J Med. 2003; 115:209-216. [EL 3]. [PubMed: 12947959]

199. Greenspan SL, von Stetten E, Emond SK, Jones L, Parker RA. Instant vertebral assessment: a noninvasive dual x-ray absorptiometry technique to avoid misclassification and clinical mismanagement of osteoporosis. J Clin Densitom. 2001; 4:373-380. [EL 2]. [PubMed: 11748342]

200. Schousboe JT, Debold CR. Reliability and accuracy of vertebral fracture assessment with densitometry compared to radiography in clinical practice. Osteoporos Int. 2006; 17:281-289. [EL 3]. [PubMed: 16172798]

201. Binkley N, Krueger D, Gangnon R, Genant HK, Drezner MK. Lateral vertebral assessment: a valuable technique to detect clinically significant vertebral fractures. Osteoporos Int. 2005; 16:1513-1518. [EL 2]. [PubMed: 15834512]

202. Schousboe JT, Vokes T, Broy SB, et al. Vertebral Fracture Assessment: the 2007 ISCD Official Positions. J Clin Densitom. 2008; 11:92-108. [EL 4]. [PubMed: 18442755]

203. Greenspan SL, Resnick NM, Parker RA. Early changes in biochemical markers of bone turnover are associated with long-term changes in bone mineral density in elderly women on alendronate, hormone replacement therapy, or combination therapy: a three-year, double-blind, placebocontrolled, randomized clinical trial. J Clin Endocrinol Metab. 2005; 90:2762-2767. [EL 1]. [PubMed: 15713726]

204. Bauer DC, Garnero P, Bilezikian JP, et al. Short-term changes in bone turnover markers and bone mineral density response to parathyroid hormone in postmenopausal women with osteoporosis. J Clin Endocrinol Metab. 2006; 91:1370-1375. [EL 1]. [PubMed: 16449339]

205. Anselmetti GC, Muto M, Guglielmi G, Masala S. Percutaneous vertebroplasty or kyphoplasty. Radiol Clin North Am. 2010; 48:641-649. [EL 4]. [PubMed: 20609898] 
206. Röllinghoff M, Zarghooni K, Dargel J, et al. The present role of vertebroplasty and kyphoplasty in the treatment of fresh vertebral compression fractures. Minerva Chir. 2010; 65:429-437. [EL 4]. [PubMed: 20802431]

207. Buchbinder R, Osborne RH, Ebeling PR, et al. A randomized trial of vertebroplasty for painful osteoporotic vertebral fractures. N Engl J Med. 2009; 361:557-568. [EL 1]. [PubMed: 19657121]

208. Kallmes DF, Comstock BA, Heagerty PJ, et al. A randomized trial of vertebroplasty for osteoporotic spinal fractures. N Engl J Med. 2009; 361:569-579. [EL 1]. [PubMed: 19657122]

209. Shindle MK, Gardner MJ, Koob J, Bukata S, Cabin JA, Lane JM. Vertebral height restoration in osteoporotic compression fractures: kyphoplasty balloon tamp is superior to postural correction alone. Osteoporos Int. 2006; 17:1815-1819. [EL 2]. [PubMed: 16983458] 


\section{$\underline{2 \text { million fractures in } 2005}$}

$73 \%$ were at nonvertebral sites

$29 \%$ occurred in men

$14 \%$ occurred in nonwhites

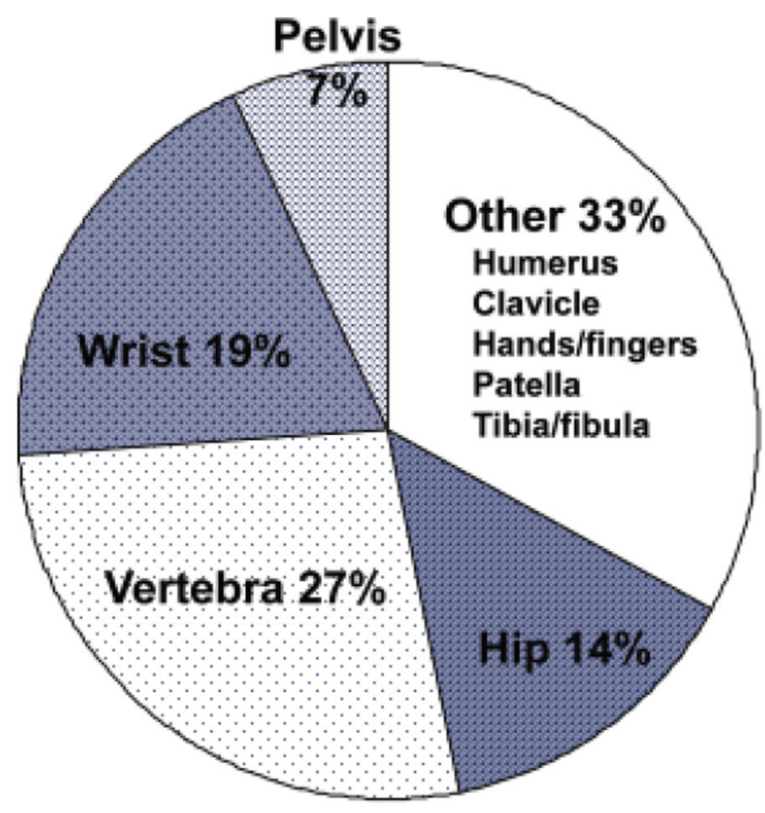

Fig. 1.

Fractures attributable to osteoporosis in the United States in 2005. Distribution by skeletal site is shown. Adapted from Burge et al (11). 
Direct cost was $\$ 16.9$ billion in 2005

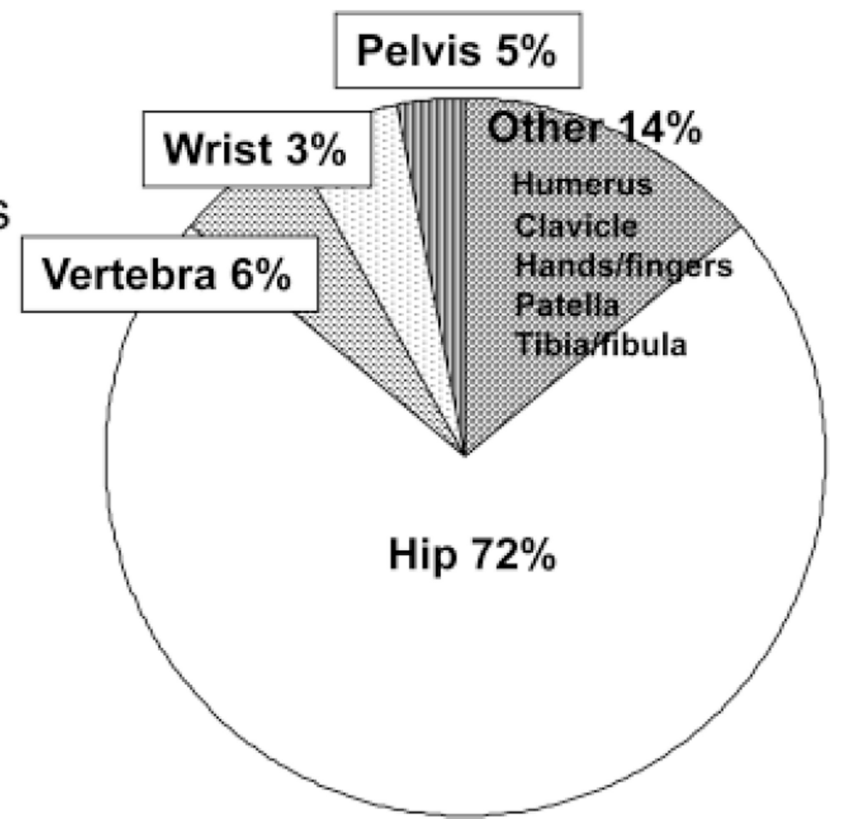

Fig. 2.

Cost of osteoporosis-related fractures in the United States in 2005. The primary site of involvement was the hip, and the preponderance of cost was for inpatient care. Adapted from Burge et al (11). 


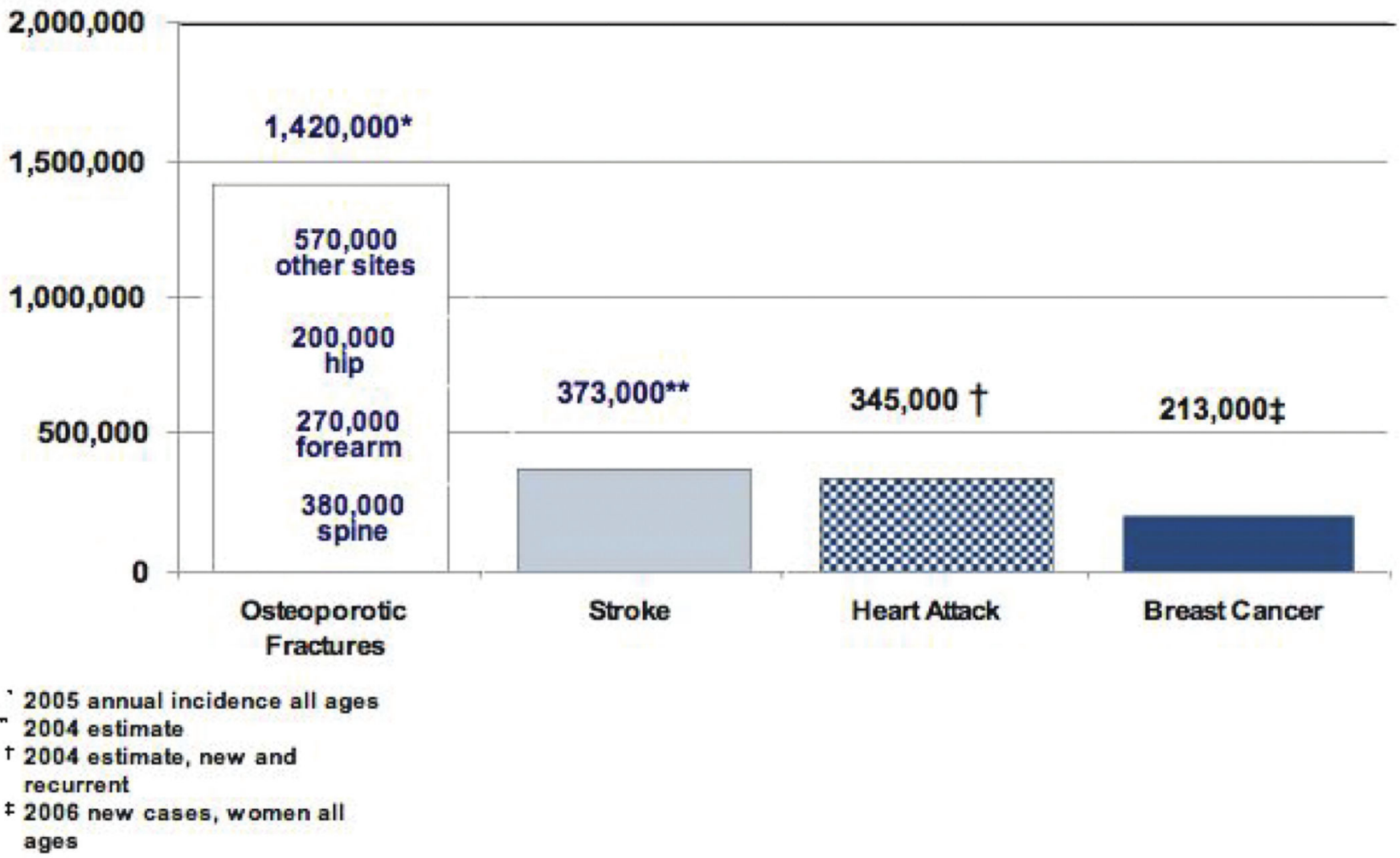

Fig. 3.

Comparative incidences of osteoporosis-related fractures, new strokes, heart attacks, and invasive breast cancer in women in the United States, based on recent statistics (2004 to 2006). Data from Burge et al (11), Rosamond et al (American Heart Association Statistics Committee and Stroke Statistics Subcommittee) (12), and American Cancer Society (13). 


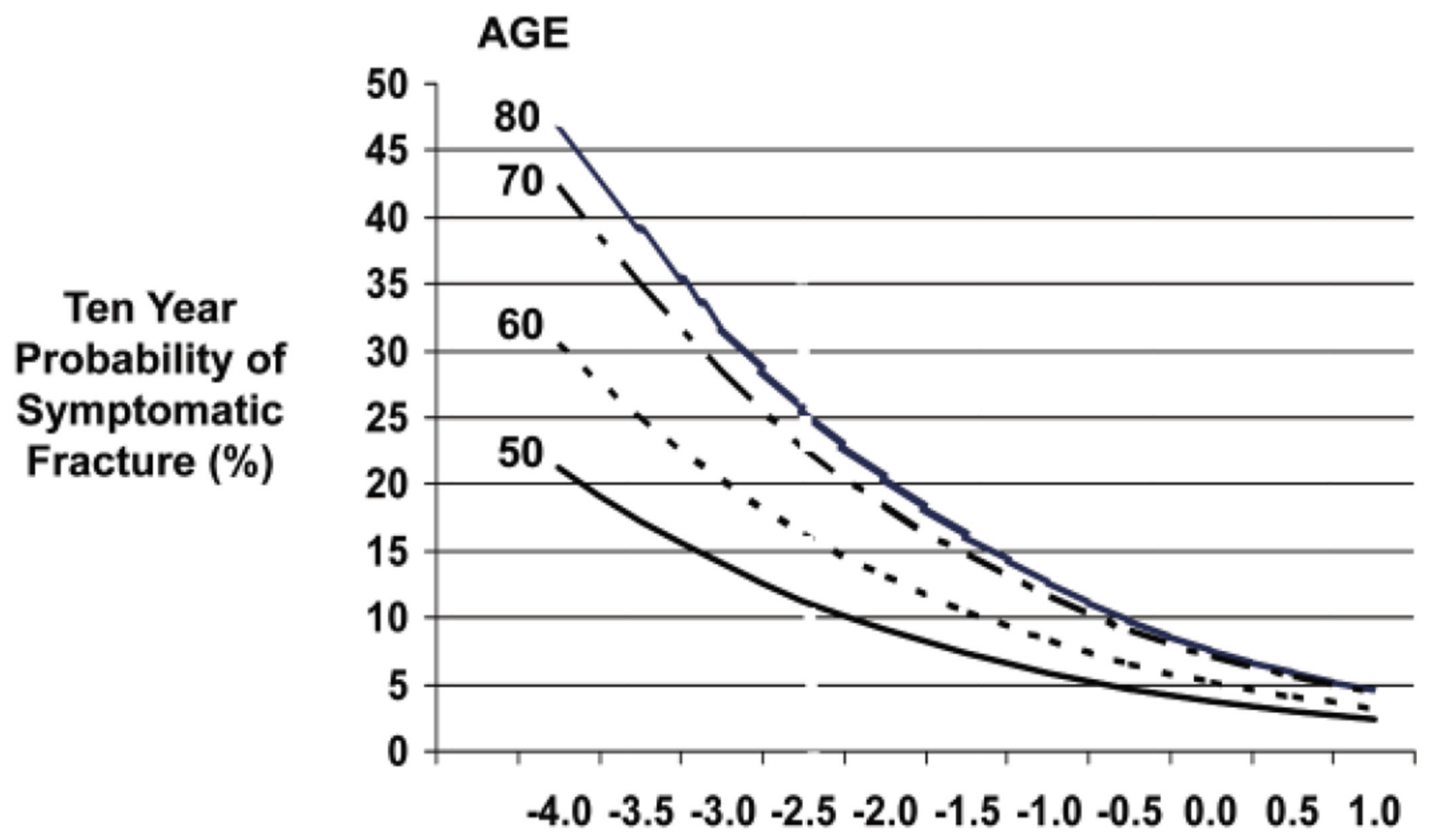

Fig. 4.

Ten-year probability of symptomatic osteoporotic fracture in adults 50 to 80 years old. The horizontal axis displays bone mineral density shown as T-scores. Adapted from Kanis et al (48). 
Table 1

2010 American Association of Clinical Endocrinologists Criteria for Rating of Published Evidence ${ }^{a}$

\begin{tabular}{|c|c|}
\hline $\begin{array}{l}\text { Numerical descriptor } \\
\text { (evidence level) }\end{array}$ & $\begin{array}{l}\text { Semantic descriptor } \\
\text { (reference methods) }\end{array}$ \\
\hline 1 & Meta-analysis of randomized controlled trials \\
\hline 1 & Randomized controlled trial \\
\hline 2 & $\begin{array}{l}\text { Meta-analysis of nonrandomized prospective or case- } \\
\text { controlled trials }\end{array}$ \\
\hline 2 & Nonrandomized controlled trial \\
\hline 2 & Prospective cohort study \\
\hline 2 & Retrospective case-control study \\
\hline 3 & Cross-sectional study \\
\hline 3 & $\begin{array}{l}\text { Surveillance study (registries, surveys, epidemiologic } \\
\text { study) }\end{array}$ \\
\hline 3 & Consecutive case series \\
\hline 3 & Single case reports \\
\hline 4 & No evidence (theory, opinion, consensus, or review) \\
\hline
\end{tabular}

${ }^{a}{ }_{1}=$ strong evidence $; 2=$ intermediate evidence; $3=$ weak evidence $; 4=$ no evidence. From Mechanick et al (1). 
Table 2

American Association of Clinical Endocrinologists Criteria for Grading of Recommendations

\begin{tabular}{|c|c|}
\hline $\begin{array}{c}\text { Recommendation } \\
\text { grade }\end{array}$ & Description \\
\hline A & $\begin{array}{l}\text { Homogeneous evidence from multiple well-designed randomized } \\
\text { controlled trials with sufficient statistical power } \\
\text { Homogeneous evidence from multiple well-designed cohort } \\
\text { controlled trials with sufficient statistical power } \\
\geq 1 \text { conclusive level } 1 \text { publications demonstrating benefit }>> \\
\text { risk }\end{array}$ \\
\hline B & $\begin{array}{l}\text { Evidence from at least } 1 \text { large well-designed clinical trial, } \\
\text { cohort or case-Controlled analytic study, or meta-analysis } \\
\text { No conclusive level } 1 \text { publication; } \geq 1 \text { conclusive level } 2 \\
\text { publications emonstrating benefit } \gg>\text { risk }\end{array}$ \\
\hline $\mathrm{C}$ & $\begin{array}{l}\text { Evidence based on clinical experience, descriptive studies, } \\
\text { or expert consensus opinion } \\
\text { No conclusive level } 1 \text { or } 2 \text { publications; } \geq 1 \text { conclusive level } \\
3 \text { publications demonstrating benefit } \gg \text { risk } \\
\text { No conclusive risk at all and no conclusive benefit } \\
\text { demonstrated by evidence }\end{array}$ \\
\hline $\mathrm{D}$ & $\begin{array}{l}\text { Not rated } \\
\text { No conclusive level 1, 2, or } 3 \text { publication demonstrating } \\
\text { benefit }>\text { risk } \\
\text { Conclusive level 1, 2, or } 3 \text { publication demonstrating risk } \\
\text { >> benefit }\end{array}$ \\
\hline
\end{tabular}

From Mechanick et al (2). 
Table 3

World Health Organization Criteria for Classification of Osteopenia and Osteoporosis

\begin{tabular}{lc}
\hline Category & T-score \\
Normal & -1.0 or above \\
Low bone mass (osteopenia) & $a$ \\
Osteoporosis & Between -1.0 and -2.5 \\
\hline
\end{tabular}

"Fracture rates within this category vary widely. The category of "osteopenia" is useful for epidemiology studies and clinical research but is problematic when applied to individual patients and must be combined with clinical information to make treatment decisions. 


\section{Table 4}

\section{Some Factors That May Accelerate Bone Loss}

Endocrine disorders
Hyperthyroidism
Hypopituitarism
Hypogonadism
Cushing disease
Primary hyperparathyroidism
Gastrointestinal disorders
Celiac disease
Short bowel syndrome
Hematologic disorders
Multiple myeloma
Systemic mastocytosis
Renal disorders
Chronic renal failure
Idiopathic hypercalciuria
Neuromuscular disorders
Muscular dystrophy
Paraplegia, quadriplegia
Proximal myopathy
Medications
Corticosteroids
Proton pump inhibitors
Antiepilepsy drugs
Medroxyprogesterone acetate (Depo-Provera)
Selective serotonin reuptake inhibitors
Thiazolidinediones
Thyroxine in supraphysiologic doses
Excess vitamin A
Aromatase inhibitors
Androgen deprivation therapy




\section{Table 5}

Some Factors That Increase Risk of Falling and Fracture

\begin{tabular}{l}
\hline Neurologic disorders \\
Parkinson disease \\
Proximal myopathy \\
Peripheral neuropathy \\
Prior stroke \\
Dementia \\
Impaired gait or balance (or both) \\
Autonomic dysfunction with orthostatic hypotension \\
Impaired vision \\
Impaired hearing \\
Frailty and deconditioning \\
Sarcopenia \\
Medications \\
Sedatives and hypnotics \\
Antihypertensive agents \\
Narcotic analgesics \\
Environmental factors \\
Poor lighting \\
Stairs \\
Slippery floors \\
Wet, icy, or uneven pavement \\
Uneven roadways \\
Electric or telephone cords \\
Phrow rositioning in a wet or dry bathtub \\
\hline
\end{tabular}


Table 6

Important Complications of Fractures

Pain

Deformity

Disability

Physical deconditioning attributable to inactivity

Changes in self-image 


\section{Table 7}

Potential Complications of Vertebral Fractures

Loss of height
Increased occiput-to-wall distance
Decreased rib-to-pelvis distance
Kyphosis (dowager's hump)
Crowding of internal organs (especially
gastrointestinal and pulmonary)
Back pain (acute and chronic)
Prolonged disability
Poor self-image, social isolation, depression
Increased mortality

Loss of height

Increased occiput-to-wall distance

Decreased rib-to-pelvis distance

gastrointestinal and pulmonary)

Back pain (acute and chronic)

Prolonged disability

Increased mortality 


\section{Table 8}

\section{Selected Risk Factors for Osteoporosis-Related Fractures}

Prior low-trauma fracture as an adult

Advanced age

Low bone mineral density

Low body weight or low body mass index (not

significant if adjusted for bone mineral density)

Family history of osteoporosis

Use of corticosteroids

Cigarette smoking

Excessive alcohol consumption

Secondary osteoporosis (for example, rheumatoid arthritis) 


\section{Table 9}

Some Causes of Secondary Osteoporosis in Adults ${ }^{a}$

\begin{tabular}{|c|c|c|c|c|}
\hline $\begin{array}{l}\text { Endocrine or } \\
\text { metabolic causes }\end{array}$ & $\begin{array}{l}\text { Nutritional/ } \\
\text { gastrointestinal } \\
\text { conditions }\end{array}$ & Drugs & $\begin{array}{l}\text { Disorders of } \\
\text { collagen } \\
\text { metabolism }\end{array}$ & Other \\
\hline $\begin{array}{l}\text { Acromegaly } \\
\text { Diabetes mellitus } \\
\text { Type } 1 \\
\text { Type } 2 \\
\text { Growth hormone deficency } \\
\text { Hypercortisolism } \\
\text { Hyperparathyroidism } \\
\text { Hyperthyroidism } \\
\text { Hypogonadism } \\
\text { Hypophosphatasia } \\
\text { Porphyria } \\
\text { Pregnancy }\end{array}$ & $\begin{array}{l}\text { Alcoholism } \\
\text { Anorexia nervosa } \\
\text { Calcium deficency } \\
\text { Chronic liver disease } \\
\text { Malabsorption syndromes/ } \\
\text { malnutrition (including } \\
\text { celiac disease, Crohn } \\
\text { disease, and gastric } \\
\text { resection or bypass) } \\
\text { Total parenteral nutrition } \\
\text { Vitamin D deficency }\end{array}$ & $\begin{array}{l}\text { Antiepileptics } b \\
\text { Aromatase inhibitors } \\
\text { Chemotheraphy/ } \\
\text { immunosuppressants } \\
\text { Depo-Provera } \\
\text { Glucocorticoids } \\
\text { Gonadotropin-releasing } \\
\text { hormone agonists } \\
\text { Heparin } \\
\text { Lithium } \\
\text { Proton pump inhibitors } \\
\text { Selective serotonin } \\
\text { reuptake inhibitors } \\
\text { Thiazolidinediones } \\
\text { Thyroid hormone (in } \\
\text { supraphysiologic } \\
\text { doses) } \\
\text { Warfarin }\end{array}$ & $\begin{array}{l}\text { Ehlers-Danlos syndrome } \\
\text { Homocystinuria due to } \\
\text { cystathionine deficency } \\
\text { Marfan syndrome } \\
\text { Osteogenesis imperfecta }\end{array}$ & $\begin{array}{l}\text { AIDS/HIV } \\
\text { Ankylosing spondylitis } \\
\text { Chronic obstructive } \\
\text { pulmonary disease } \\
\text { Gaucher disease } \\
\text { Hemophilia } \\
\text { Hypercalciuria } \\
\text { Immobilization } \\
\text { Major depression } \\
\text { Myeloma and some } \\
\text { cancers } \\
\text { Organ transplantation } \\
\text { Renal insufficiency/ } \\
\text { failure } \\
\text { Renal tubular acidosis } \\
\text { Rheumatoid arthritis } \\
\text { Systemic mastocytosis } \\
\text { Thalassemiai }\end{array}$ \\
\hline
\end{tabular}

${ }^{a}$ AIDS = acquired immunodeficency syndrome; HIV = human immunodeficency virus.

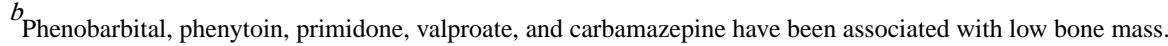


Table 10

\begin{tabular}{|c|c|c|}
\hline Age & Sex & $\begin{array}{r}\text { Recommended } \\
\text { dietary allowance } \\
(\mathrm{mg} / \mathrm{d})\end{array}$ \\
\hline $0-6$ mo & $\mathrm{M}+\mathrm{F}$ & 200 \\
\hline 6-12 mo & $\mathrm{M}+\mathrm{F}$ & 260 \\
\hline $1-3 y$ & $\mathrm{M}+\mathrm{F}$ & 700 \\
\hline $4-8$ y & $\mathrm{M}+\mathrm{F}$ & 1,000 \\
\hline $9-18$ y & $\mathrm{M}+\mathrm{F}$ & 1,300 \\
\hline $19-50$ y & $M+F$ & 1,000 \\
\hline $51-70$ y & M & 1,000 \\
\hline $51-70$ y & F & 1,200 \\
\hline $71+y$ & $M+F$ & 1,200 \\
\hline
\end{tabular}

From Ross et al (53). Reproduced with permission. 


\section{Table 11}

Some Measures for Prevention of Falls

\begin{tabular}{l}
\hline Anchor rugs \\
Minimize clutter \\
Remove loose wires \\
Use nonskid mats \\
Install handrails in bathrooms, halls, and long stairways \\
Light hallways, stairwells, and entrances \\
Encourage patient to wear sturdy, low-heeled shoes \\
Recommend hip protectors for patients who are \\
predisposed to falling
\end{tabular}


Table 12

Recommendations Regarding Lifestyle Issues

Ensure adequate intake of calcium throughout life

Ensure adequacy of vitamin D intake

Consume a balanced diet

Regularly perform weight-bearing exercises

Avoid use of tobacco

Limit alcohol consumption

Take measures to avoid falls

Consider use of hip protectors 
Table 13

Measures for Risk Assessment in Postmenopausal Women ${ }^{a}$

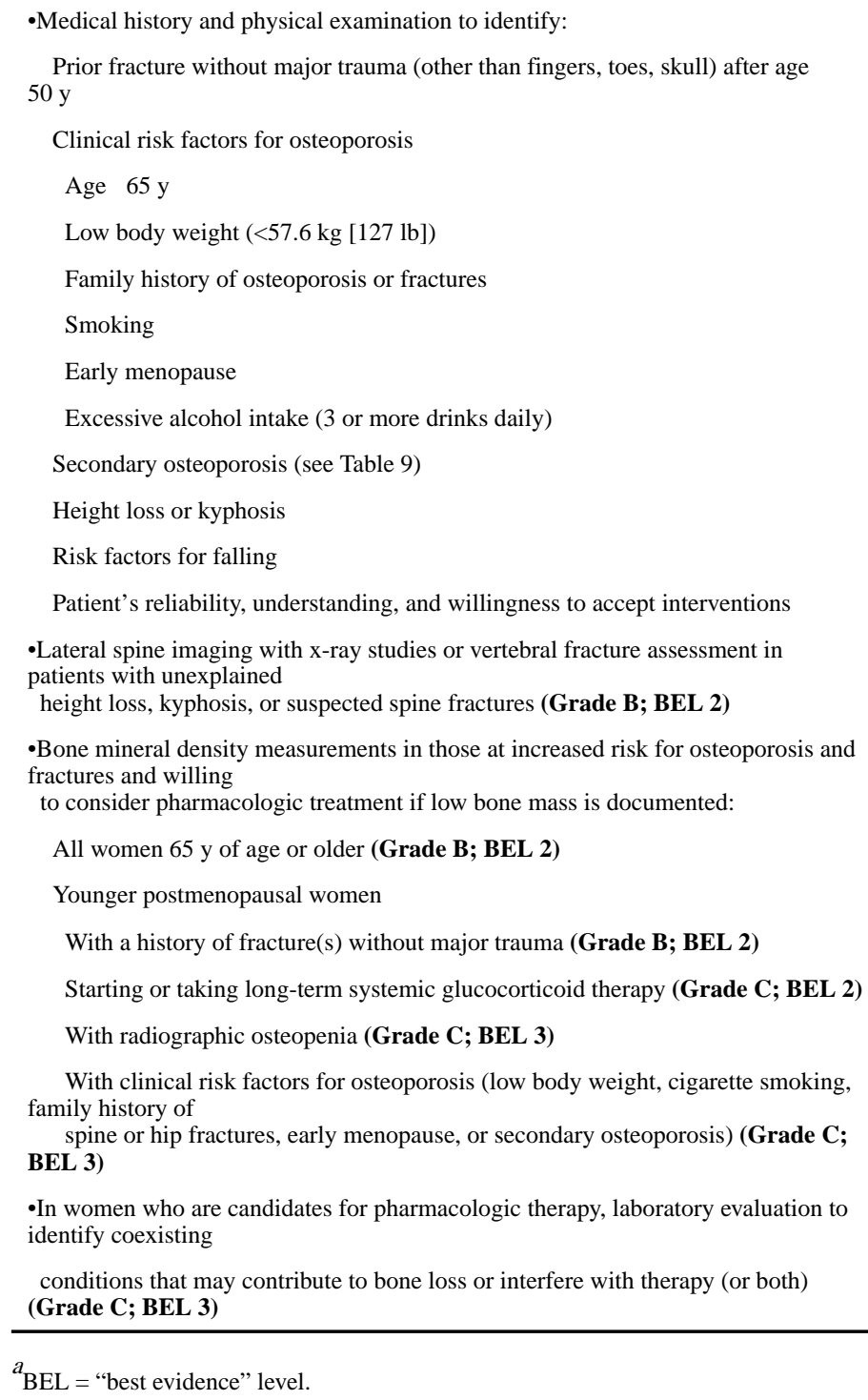

With clinical risk factors for osteoporosis (low body weight, cigarette smoking, family history of

spine or hip fractures, early menopause, or secondary osteoporosis) (Grade C; BEL 3)

-In women who are candidates for pharmacologic therapy, laboratory evaluation to identify coexisting

conditions that may contribute to bone loss or interfere with therapy (or both) (Grade C; BEL 3)

${ }^{a} \mathrm{BEL}=$ "best evidence" level. 
Table 14

Bone Mineral Density Measurements: Potential Uses in Postmenopausal Women

\begin{tabular}{l} 
Screening for osteoporosis \\
Establishing the severity of osteoporosis or bone loss \\
in patients with suspected osteoporosis (for example, \\
patients with fractures or radiographic evidence of \\
osteopenia) \\
Determining fracture risk-especially when combined \\
with other risk factors for fractures (see Table 8) \\
Identifying candidates for pharmacologic intervention \\
Assessing changes in bone mass over time in treated \\
and untreated patients \\
Enhancing acceptance of, and perhaps adherence with, \\
treatment \\
Assessing skeletal consequences of diseases, conditions, \\
or medications known to cause bone loss \\
\hline
\end{tabular}


Table 15

\section{Indications for Bone Mineral Density Testing}

All women 65 y of age or older
All postmenopausal women
With a history of fracture(s) without major trauma after age 40 to $45 \mathrm{y}$
With osteopenia identified radiographically
Starting or taking long-term systemic glucocorticoid therapy ( $\geq 3$ mo)
Other perimenopausal or postmenopausal women with risk factors for
osteoporosis if willing to consider pharmacologic interventions
Low body weight ( $<127$ lb or body mass index $<20 \mathrm{~kg} / \mathrm{m}^{2}$ )
Ever use of long-term systemic glucocorticoid therapy ( $\geq 3 \mathrm{mo}$ )
Family history of osteoporotic fracture
Early menopause
Current smoking
Excessive consumption of alcohol
Secondary osteoporosis (see Table 9 )


Table 16

Laboratory Tests to Consider in Screening for Secondary Osteoporosis

Complete blood cell count
Serum chemistry, including calcium, phosphorus, total protein,
albumin, liver enzymes, alkaline phosphatase, creatinine, and
electrolytes
Urinalysis (24-h collection) for calcium, sodium, and creatinine
excretion (to identify calcium malabsorption or hypercalciuria)
Serum 25-hydroxyvitamin D


Table 17

\section{Tests for Secondary Osteoporosis to Be Considered If There Is Clinical Suspicion}

Serum thyrotropin

Erythrocyte sedimentation rate

Serum parathyroid hormone concentration for possible primary or secondary

hyperparathyroidism

Tissue transglutaminase antibodies for suspected celiac disease

Urinary free cortisol or other tests for suspected adrenal hypersecretion

Acid-base studies

Serum tryptase, urine N-methylhistamine, or other tests for mastocytosis

Serum protein electrophoresis and free kappa and lambda light chains for suspected myeloma

Bone marrow aspiration and biopsy to look for marrow-based diseases

Undecalcified iliac crest bone biopsy with double tetracycline labeling

Recommended for patients with bone disease and renal failure to establish the correct diagnosis and direct management

May be helpful in the assessment of patients with the following:

Suspected osteomalacia or mastocytosis when laboratory test results are inconclusive

Fracture without major trauma despite normal or high bone density

Vitamin D-resistant osteomalacia and similar disorders to assess response to treatment

Unusual features that suggest a rare metabolic bone disease 
Table 18

\title{
Measures for Decreasing the Risk of Osteoporosis and Fractures in High-Risk Women
}

\author{
Identify and treat women with osteoporosis-related fractures, and consider \\ pharmacologic therapy for women with low bone mass \\ Identify and treat sensory defects, neurologic disease, and arthritis, which \\ can contribute to frequency of falls \\ Adjust dosage of drugs with sedative effects, which could slow reflexes or \\ decrease coordination and impair patient's ability to break impact of a fall \\ Recommend appropriate lifestyle changes, including smoking cessation, \\ increased weight-bearing activities, and dietary improvements \\ Minimize risk of falls and injuries with gait and balance training
}




\section{롤 \\ 골}

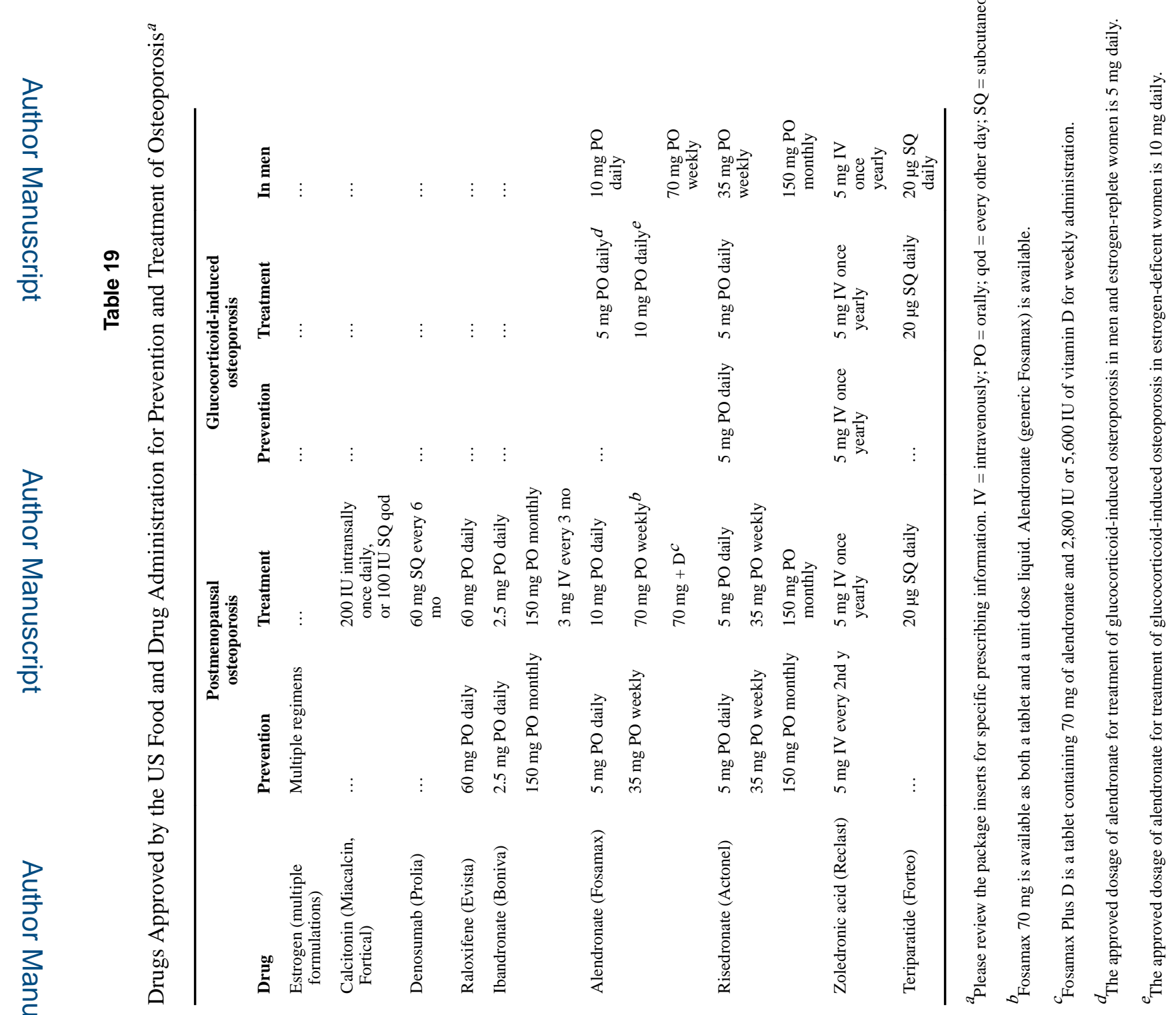


Table 20

Summary of Evidence for Fracture Risk Reduction

\begin{tabular}{|c|c|c|c|}
\hline \multirow[b]{2}{*}{ Drug } & \multirow[b]{2}{*}{ Vertebral } & \multicolumn{2}{|l|}{ Fracture risk reduction } \\
\hline & & Nonvertebral & Hip \\
\hline Calcitonin (Miacalcin, Fortical) & Yes & No effect demonstrated ${ }^{a}$ & $\begin{array}{l}\text { No effect } \\
\text { demonstrated }^{a}\end{array}$ \\
\hline Raloxifene (Evista) & Yes & No effect demonstrated ${ }^{a}$ & $\begin{array}{l}\text { No effect } \\
\text { demonstrated }^{a}\end{array}$ \\
\hline Ibandronate (Boniva) & Yes & No effect demonstrated ${ }^{a}$ & $\begin{array}{l}\text { No effect } \\
\text { demonstrated }^{a}\end{array}$ \\
\hline Alendronate (Fosamax) & Yes & Yes & Yes \\
\hline Risedronate (Actonel) & Yes & Yes & Yes \\
\hline Zoledronic acid (Reclast) & Yes & Yes & Yes \\
\hline Denosumab (Prolia) & Yes & Yes & Yes \\
\hline Teriparatide (Forteo) & Yes & Yes & $\begin{array}{l}\text { No effect } \\
\text { demonstrated }^{a}\end{array}$ \\
\hline
\end{tabular}

${ }^{a}$ The lack of demonstrable effect at these sites should be considered in the context that the studies may not have been adequately powered. 